Portland State University

PDXScholar

$1-1-2010$

\title{
Exploratory Eddy Covariance Measurements of Surface Heat and CO2 Fluxes in the Roughness Sublayer of an Urban Environment
}

Benjamin F. Burnett

Portland State University

Follow this and additional works at: https://pdxscholar.library.pdx.edu/open_access_etds

Let us know how access to this document benefits you.

\section{Recommended Citation}

Burnett, Benjamin F., "Exploratory Eddy Covariance Measurements of Surface Heat and CO2 Fluxes in the Roughness Sublayer of an Urban Environment" (2010). Dissertations and Theses. Paper 401.

https://doi.org/10.15760/etd.401

This Thesis is brought to you for free and open access. It has been accepted for inclusion in Dissertations and Theses by an authorized administrator of PDXScholar. Please contact us if we can make this document more accessible: pdxscholar@pdx.edu. 
Exploratory Eddy Covariance Measurements of Surface Heat and $\mathrm{CO}_{2}$

Fluxes in the Roughness Sublayer of an Urban Environment

By

Benjamin F. Burnett

A thesis submitted in partial fulfillment of the requirements for the degree of

\author{
Master of Science \\ in \\ Mechanical Engineering
}

Thesis Committee:

David Sailor, Chair

Raúl Bayoán Cal

Gerald Recktenwald

Portland State University

(C)2010 


\begin{abstract}
In this study eddy covariance was used to measure sensible heat, latent heat, and carbon dioxide fluxes for the months of August, September, and October of 2009 within the roughness sublayer (RSL) of the urban center of Portland, OR. Vehicle traffic and solar radiation were also measured for the month of October. Flux measurements were compared with measurements from other urban areas as a test of reasonableness. $\mathrm{CO}_{2}$ fluxes were nearly always positive and were strongly correlated with the weekday diurnal traffic cycle. $\mathrm{CO}_{2}$ fluxes averaged $6.6 \mu \mathrm{mol} / \mathrm{m}^{2} \mathrm{~s}$, which is less than other published measurements in urban areas. Sensible and latent heat fluxes followed the expected diurnal profile associated with solar radiation. Average sensible heat flux decreased as the season changed from summer to fall, moving from an average of 39 $\mathrm{W} / \mathrm{m}^{2}$ in August to $12 \mathrm{~W} / \mathrm{m}^{2}$ in October. A corresponding increase in latent heat flux was observed during this period, changing from an average of $10 \mathrm{~W} / \mathrm{m}^{2}$ in August to 17 $\mathrm{W} / \mathrm{m}^{2}$ in October. Heat flux behavior and amplitude was consistent with other urban measurements, though amplitude varies considerably from city to city. Stationarity was shown to positively influence measured $\mathrm{CO}_{2}$ fluxes, but to have little effect on measured heat fluxes. Preliminary comparisons of October sensible heat and $\mathrm{CO}_{2}$ fluxes to an inventory-based estimate of vehicle emissions indicate that eddy covariance measurements underestimate the true fluxes by $50 \%$.
\end{abstract}




\section{Acknowledgements}

I would like to thank David Sailor for admitting me into the program and providing scientific motivation and funding for my research.

Oregon Best, the PSU Center for Sustainable Processes and Practices, and the Miller Foundation also deserve credit for funding my research.

I would also like to thank the City of Portland Department of Transportation for providing traffic measurements. 


\section{Table of Contents}

Abstract i

Acknowledgements

List of Tables

iv

List of Figures v

1. Introduction 1

2. The Eddy Covariance Method 13

3. Method 34

4. Results and Discussion 44

5. Conclusions 63

References 66

Appendix A: Displacement Height Calculations 71 


\section{List of Tables}

Table 1: Monthly weather for 2009. 38

Table 2: Instrument outputs and resolutions. 40

Table 3: Filter criteria for half-hour blocks. 43

Table 4: Monthly wind speed. 44

Table 5: Rejection of half-hour blocks by category. 46

Table 6: $\mathrm{CO}_{2}$ concentration and flux statistics. 47

Table 7: Monthly sensible and latent heat flux statistics. 56

Table 8: Regression results for incident solar radiation and traffic count versus sensible heat flux. 59 


\section{List of Figures}

Figure 1: Surface energy balance, as adapted from Sailor (2010). 2

Figure 2: Example of a SEB from Grimmond et al. (2004). 4

Figure 3: Ideal measurement height above an urban surface (Walsh et al., 2004). 7

Figure 4: Visualization of fetch for a flux sensor. (Burba \& Anderson, 2005) 8

Figure 5: Relationship between measurement height and fetch length adapted from Gash (1986). 9

Figure 6: Eddy covariance instruments. 19

Figure 7: Atmospheric turbulence spectrum from Foken (2008a). 21

Figure 8: Processing procedure. 23

Figure 9: The two-rotation method in Eqs. (13) and (14). 24

Figure 10: Planar fit example from Paw U et al. (2000). 26

Figure 11: Ogives for sensible heat flux at measurement heights of a) $396 \mathrm{~m}$, b) $122 \mathrm{~m}$, and c) $30 \mathrm{~m}$. (Berger et al., 2001) 27

Figure 12: A comparison of an idealized atmospheric cospectrum versus their measurement by an eddy covariance system (Lee et al., 2004). 29

Figure 13: City Center of Portland, Oregon. Image courtesy of City of Portland. 35

Figure 14: Accepted wind zones. Image courtesy of City of Portland 37

Figure 15: Instruments mounted on the FAB roof. 39

Figure 16: Wind frequency for August, September, and October 2009. 45 
Figure 17: Average diurnal pattern of $\mathrm{CO}_{2}$ concentration for August (A), September (B), and October (C) 2009.

Figure 18: Average diurnal pattern of $\mathrm{CO}_{2}$ flux for August (A), September (B), and October (C) 2009. 49

Figure 19: Average CO2 flux and traffic count for weekdays in October. 52

Figure 20: Combined diurnal $\mathrm{CO}_{2}$ flux profile for August, September, and October. 52

Figure 21: Sensible and latent heat flux profiles for August. 54

Figure 22: Sensible and latent heat flux profiles for September. 54

Figure 23: Sensible and latent heat flux profiles for October. 55

Figure 24: Average daily profile of energy flux and traffic for October. 56

Figure 25: Combined diurnal sensible heat flux profile for August, September, and October. 57

Figure 26: Combined diurnal latent heat flux profile for August, September, and October. 57

Figure 27: Representative unit chosen for estimating heat from vehicles. Image courtesy of City of Portland. 60

Figure 28: Weekday traffic count versus $\mathrm{CO}_{2}$ Flux. 62 


\section{Introduction}

The study is motivated by a desire to understand the surface energy balance (SEB) in a dense urban environment. One of the important components of the SEB is vertical heat flux. Eddy covariance, the most established technique for measuring vertical heat fluxes, is difficult to apply in dense urban environments without violating criteria for sensor placement. Specifically, the requirement for minimum sensor height is not met. As a result, few studies of this type have been attempted. This study will compare measured values of heat and $\mathrm{CO}_{2}$ fluxes to inventory based emissions from vehicles in an attempt to gauge the validity of measurements made in the RSL.

\subsection{Motivation}

Urban centers are often measurably warmer than their suburban and rural counterparts. This urban heat island (UHI) has negative impacts on air pollution, building energy use, and human comfort. Causes of these higher temperatures include, but are not limited to, urban-rural differences in albedo, vegetation cover, thermal storage, and anthropogenic heating. In order to understand the magnitude of the UHI and possible mitigation techniques, it is important to understand the surface energy balance (SEB). The SEB is essentially a control volume extruded from a surface of interest (Figure 1). In an urban setting, it is generally expressed as (Oke, 1988):

$$
Q^{*}+Q_{F}=Q_{H}+Q_{E}+\Delta Q_{S}+\Delta Q_{A}+S
$$




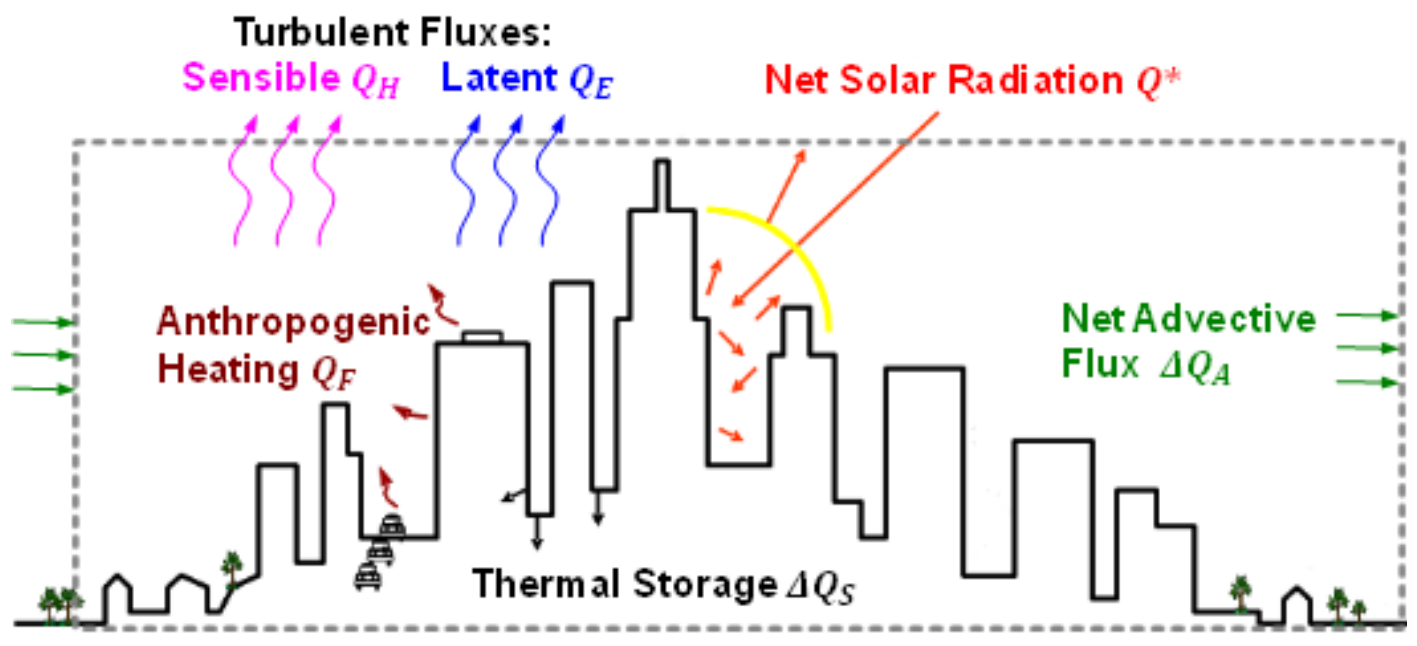

Figure 1: Surface energy balance, as adapted from Sailor (2010).

$Q^{*}$ is the net solar energy through the top surface of the volume. It is generally divided into shortwave and longwave radiation at a wavelength of approximately $3 \mu \mathrm{m}$. The majority of the sun's energy output is emitted as shortwave radiation. Longwave radiation is characterized as infrared (heat) radiation emitted from terrestrial objects, from clouds to surface elements (Foken, 2008a). $Q^{*}$ can be further decomposed into four components: Incident shortwave $K \downarrow$, reflected shortwave $K \uparrow$, incident longwave $I \downarrow$, and emitted longwave $I \uparrow$, such that:

$$
Q^{*}=K \downarrow+K \uparrow+I \downarrow+I \uparrow
$$

The arrow convention indicates whether the flux is point towards the surface (down arrows) or away from the surface (up arrows). $Q_{F}$ is anthropogenic heating, or heat related to human activity: Vehicle emissions, building emissions, and human metabolism. $Q_{H}=C_{1} \overline{w^{\prime} T^{\prime}}$, and $Q_{E}=C_{2} \overline{w^{\prime} \rho_{v}^{\prime}}$ represent the vertical transfer of sensible and latent heat, respectively, through the top surface of the control volume by 
turbulent, or fluctuating flow. $C_{1}$ and $C_{2}$ are constants based on heat capacities, $w^{\prime}$ is the vertical velocity fluctuation, $T^{\prime}$ is the temperature fluctuation, and $\rho_{v}^{\prime}$ is the fluctuation in water vapor concentration. These equations are more thoroughly described in Section 2.1. Net heat storage $\Delta Q_{S}$ represents heat, primarily from solar radiation, that is absorbed and temporarily stored by mass inside the volume. This heat is then either convected from the surface, where it contributes to $Q_{H}$ or $\Delta Q_{A}$, or is emitted as longwave radiation, where it contributes to $I \uparrow$. Net advective flux $\Delta Q_{A}=\bar{x}(\bar{H}+\bar{E})$ represents net sensible $(\bar{H})$ and latent $(\bar{E})$ heat transport through the vertical faces by mean horizontal flow $\bar{x}$. S represents any miscellaneous energy sources or sinks. $Q^{*}$ and $Q_{F}$ are placed on the left hand side of the equation because they are considered to be energy sources. The terms on the right hand side may move energy into or out of the volume, but do not generate energy except in special cases where an additional source $S$ is identified.

Figure 2 shows daily average surface energy balance measurements taken from June 16 to July 142001 in Marseille, France (Grimmond et al., 2004). A clear diurnal pattern driven by solar radiation is present. $Q^{*}$ is the dominant energy flux, followed in order by $Q_{H}, \Delta Q_{S}, Q_{E}$, and $Q_{F}$. Advective flux $\Delta Q_{A}$ was taken to be zero in the Marseille study. These relative magnitudes are typical of SEB measurements. Due to variations in climate, surface vegetation cover, and anthropogenic heat sources in different cities or even from season to season in the same location, they should not be taken to be definitive. 


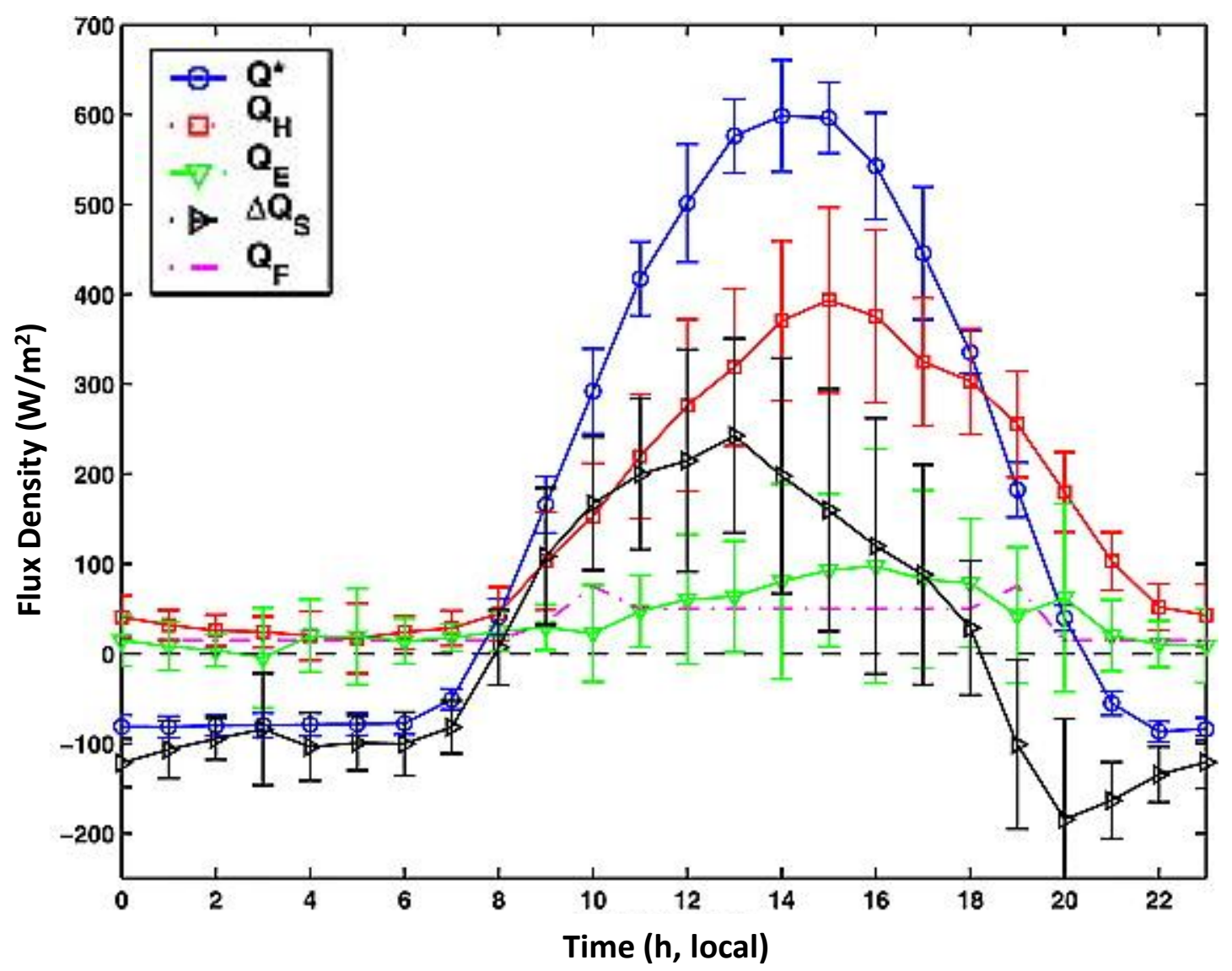

Figure 2: Example of a SEB from Grimmond et al. (2004). Measurements were taken from June 16 to July 142001 in Marseille, France. Error bars represent standard deviations of the half-hourly measurements. The daily profiles and relative magnitudes are typical of the terms in Eq. (1). $\Delta Q_{A}$ was assumed to be zero and is absent.

Of the seven terms in Eq. (1) only three are explicitly measured in most studies:

Solar radiation $Q^{*}$, and the turbulent heat fluxes $Q_{H}$ and $Q_{E}$. It is generally assumed that $\Delta Q_{S}=0$ over 24-hour periods. If temporal resolution of $\Delta Q_{S}$ smaller than one day is desired, this term can be estimated by combining surface temperature measurements with a heat conduction model (Masson, 2000); (Offerle et al., 2005). Net advective flux $\Delta Q_{A}$ is assumed to be zero in uniform terrain, where the upwind temperature, wind speed, and constituent density profiles are presumed to be the same at the inlet and 
exit faces of the control volume. Dense urban cores, with their horizontally and vertically heterogeneous geometry, fail to meet this criteria. A second argument for neglecting $\Delta Q_{A}$ is that the horizontal area measured is much larger than the vertical area through which $\Delta Q_{A}$ passes. However, even in cases where the horizontal area is much larger and terrain and energy sources are horizontally homogeneous, horizontal scalar gradients may exist such that advection must be considered (Paw U et al., 2000). Because of the large number of anthropogenic heat sources, $Q_{F}$ cannot reasonably be measured directly. Two different approaches have been used to estimate $Q_{F}$. The first involves taking inventories of energy consumption over an urban or suburban area. This approach has been used in Vancouver B.C. (Grimmond, 1992), Tokyo (Ichinose et al., 1999), and various American cities (Sailor \& Lu, 2004), for example, though this is by no means an exhaustive list. The disadvantage of the inventory approach is that both spatial and temporal resolutions tend to be low. Spatial resolution is typically on the scale of a city. Temporal resolution is typically monthly, though other information such as occupancy schedules and traffic profiles can be used to estimate temporal profiles at smaller scales (Sailor \& Lu, 2004). The second approach for estimating $Q_{F}$ is based on SEB measurements, where Eq. (1) is rearranged so that $Q_{F}$ is the residual of the other terms:

$$
Q_{F}=-Q^{*}+Q_{H}+Q_{E}+\Delta Q_{S}+\Delta Q_{A}+S
$$

This approach yields values for $Q_{F}$ at hourly (or smaller) time scales and neighborhood spatial scales. Unfortunately, the errors associated with the measurements on the right- 
hand side of Eq. (3) may be as large or larger than the magnitude of $Q_{F}$ (Foken, 2008b). Comparisons of the inventory and SEB methods tend to show good agreement in winter months, while the SEB tends to underestimate anthropogenic heating in summer (Offerle et al., 2005); (Pigeon et al., 2007).

The measurement of turbulent fluxes clearly plays an important role in understanding the energy balance. The most established method for measuring turbulent fluxes is the eddy covariance method. It uses high speed measurements of three-dimensional wind speed, temperature, and gas concentrations to provide direct, in situ measurements at a point. The method is described in detail in Chapter 2. The concept was first proposed and tested in 1951, but instrumentation challenges delayed its practical use until it was adopted for forest and agricultural studies in the early 1980's (Aubinet et al., 2000). A large number of published studies have validated this technique in uniform, rural terrain, e.g. (Baldocchi et al., 1988), (Foken \& Wichura, 1996), and an extensive list can be found in (Aubinet et al., 2000). Even so, problems with closing the energy balance remain (Foken, 2008b).

A lack of large, uniform areas combined with tall vertical features poses additional challenges to eddy covariance applications in urban areas. While some of these challenges are related to the underlying assumptions of eddy covariance (see Chapter 2), an even more fundamental issue involves atmospheric point measurements and source areas. In order for a point measurement to be representative of the flux through a horizontal plane at the sensor height, the sensor must be placed high enough that it is 


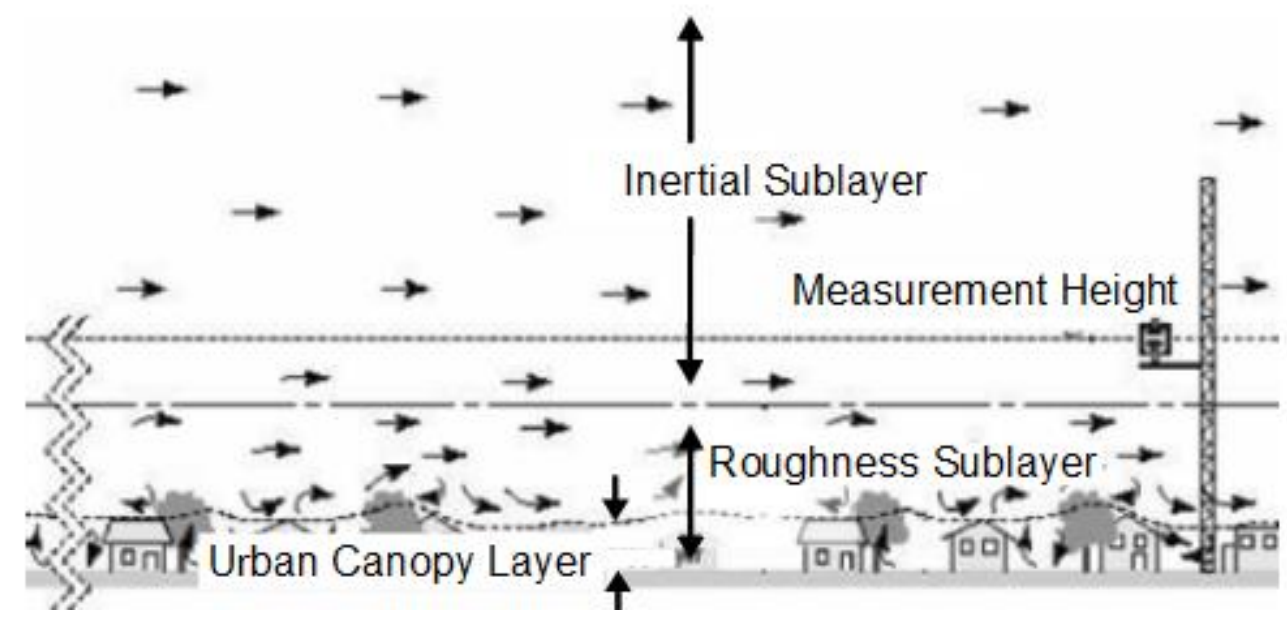

Figure 3: Ideal measurement height above an urban surface (Walsh et al., 2004).

not subject to localized flows (e.g. recirculation zones from building wakes). The lower atmospheric boundary layer in urban or suburban terrain is typically divided into three segments (Figure 3): An urban canopy layer (UCL) extending from ground level to the tops of buildings, a roughness sublayer (RSL) extending from ground level to roughly 2-3 times the local building height, and an inertial sublayer (ISL) extending up from the top of the RSL. The RSL is the rough-wall counterpart of the viscous sublayer over smooth walls, and can be thought of as the area where the individual roughness elements have a direct dynamical influence on the flow and turbulence (Raupach et al., 1991). The vertical extent of the RSL is dependent on roughness element height and spacing, wind speed, and thermal stratification. A review of both wind tunnel and field measurements placed the height of the RSL anywhere from 1.5 to 4.5 times the height of the roughness elements (Rotach, 1999). The ISL is also known as the constant flux layer (CFL), because the vertical flux component is independent of height. The upper boundary of the RSL 
sets a lower limit on sensor height, so that the sensor is within the CFL. The upper limit on sensor height is set by the effective fetch, or upwind source length. Fetch, sometimes referred to as fetch length, can be thought of as the horizontal distance from the sensor that the sensor "sees" (Burba \& Anderson, 2005). A visualization of this quantity is shown in Figure 4. Because the contribution as a function of distance is nonlinear, the fetch length is usually defined in terms of a "percent effective fetch," a length that encompasses a percentage $F$ of the total measurement. As the measurement height increases, the effective fetch that contributes to the measured

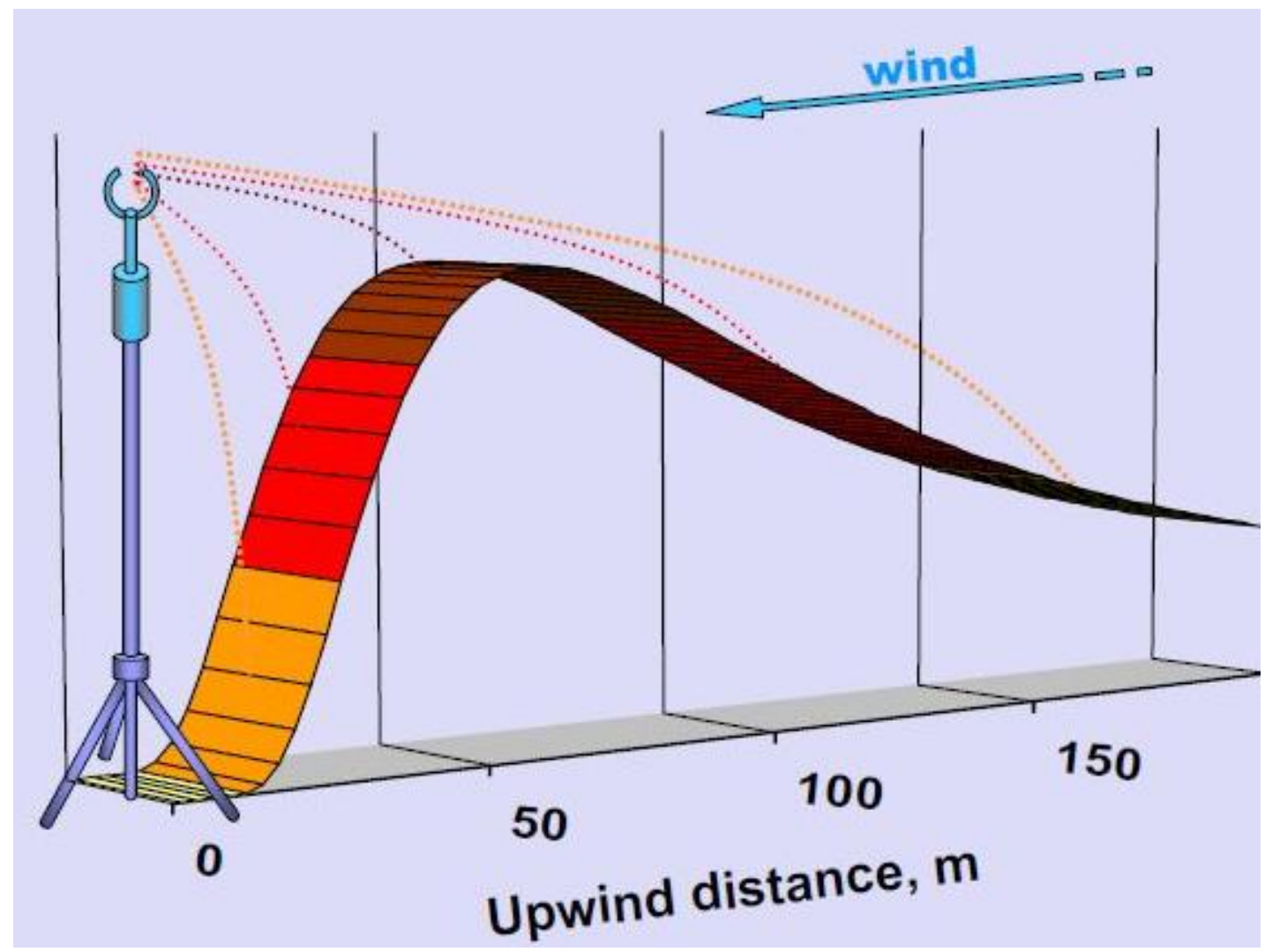

Figure 4: Visualization of fetch for a flux sensor. The vertical direction represents the relative contribution to the measured fluxes from each distance (Burba \& Anderson, 2005). 
variables also increases. For example, a simple, two-parameter equation for a percentage $F$ effective fetch in uniform terrain is (Gash, 1986):

$$
x_{F}=-\frac{z_{m}\left(\ln \left(z_{m} / z_{0}\right)-1+z_{0} / z_{m}\right)}{\kappa^{2} \ln (F / 100)}
$$

where $x_{F}$ is the fetch length, $z_{m}$ is the measurement height (sensor height minus displacement height), and $z_{0}$ is the aerodynamic roughness length, and $\kappa=0.4$ is the Von Karman constant. Figure 5 shows how the ratio $x_{F} / z_{m}$ increases with measurement height. Roughness length $z_{0}$ is formally defined as the height of an extrapolated logarithmic wind profile $u(z)$ where $u\left(z_{0}\right)=0$. It can be estimated as a function of the geometric surface structure or calculated from measurements of turbulence near the surface (Foken, 2008a). The simplest estimate of $z_{0}$ from the

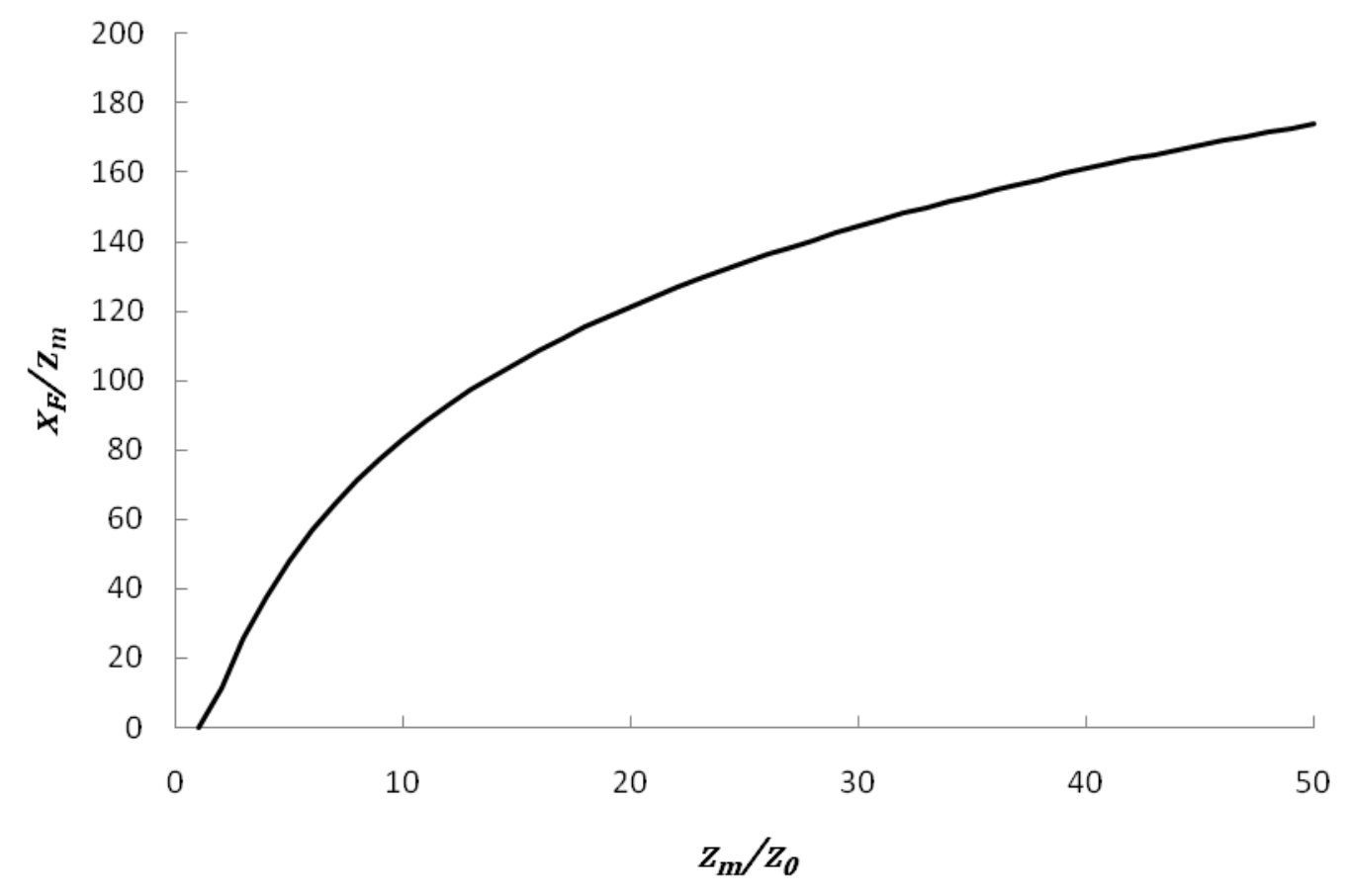

Figure 5: Relationship between measurement height and fetch length adapted from Gash (1986). 
surface structure is simply to take $10 \%$ of the average height of the roughness elements, in this case, buildings (Grimmond \& Oke, 1999). While this is a rough estimate, it suggests that the ratio $z_{m} / \mathrm{z}_{0}$ will not generally be less than 10 . Applying this assumption to Figure 5 , the ratio $x_{F} / z_{m}$ ranges from 80 to 175 . In a dense urban area with tall buildings, the ratio of the longest possible "uniform" fetch (or the long axis of the largest area of interest) to the height of the tallest buildings is often much lower than this. In Portland, for example, the ratio of the longest possible fetch $(2 \mathrm{~km})$ to the height of the tallest buildings $(110 \mathrm{~m})$ is approximately 20 . As a result, any measurements made above the roughness sublayer will measure a source area much larger than the area of interest.

\subsection{Purpose}

Measuring vertical fluxes in a dense urban environment with tall structures is clearly problematic. Relatively few published studies of vertical fluxes (heat or $\mathrm{CO}_{2}$ ) in urban environments are available. Nearly all of the published flux measurements in cities deal with the sensor height restriction by selecting sites with relatively low buildings and little vertical variation. Some accomplish this by placing the sensors in a suburban location, as in Chicago (Grimmond et al., 2002), Baltimore (Grimmond et al., 2002), and Vancouver (Walsh et al., 2004). Others located sensors in dense urban areas that contain few or no high-rise structures, as in Edinburgh (Nemitz et al., 2002), Marseille 
(Grimmond et al., 2004), Mexico City (Velasco et al., 2005), and Łódź (Offerle et al., 2005).

Only one study was found where measurements within the RSL were attempted. The Basel UrBan Boundary Layer Experiment (BUBBLE) was a year-long experimental effort to investigate in detail the boundary layer structure in the city of Basel, Switzerland (Rotach et al., 2005). Results for both sensible heat fluxes (Christen \& Vogt, 2004) and $\mathrm{CO}_{2}$ fluxes (Vogt et al., 2006) have been published as part of BUBBLE. Sensible heat fluxes were measured with sonic anemometers at six different heights on a single tower in an urban street canyon. Anemometer heights ranged from $3.7 \mathrm{~m}$ to $31.7 \mathrm{~m}$, measured from ground level. Sensors at lower heights tended to measure much less heat flux, with measurements at $14.7 \mathrm{~m}$ accounting for approximately $20 \%$ of the flux measured at $31.7 \mathrm{~m}$. This apparent discrepancy was explained by models and measurements of solar radiation, which showed that only $15 \%$ of incident shortwave radiation reached ground level. Solar radiation is the primary driver of sensible heat flux. Consequently the cumulative contribution from surface elements to the total sensible heat flux increases with height (Christen \& Vogt, 2004). $\mathrm{CO}_{2}$ fluxes were measured from two eddy covariance sensor packages at different heights on the same tower as the sensible heat flux measurements. The lower sensor was mounted at 14.7 $m$ from the ground surface, at the top of the urban street canyon. The higher sensor was mounted at a height of $31.7 \mathrm{~m}$ above ground level. Diurnal $\mathrm{CO}_{2}$ flux profiles from the two sensors were identical in shape, with the higher sensor measuring larger flux at 
night, while the lower sensor measured larger fluxes during the day. This behavior was explained by the relative source areas of the two sensors. The lower sensor primarily measured the concentrated traffic emissions of the street canyon, while the higher sensor measured a larger portion of the city surface with fewer emissions per unit area (Vogt et al., 2006). The results from Basel suggest that the eddy covariance technique can yield valid data, even when used within the RSL. The purpose of this study is (1) to add to the very sparse data set of measured heat and $\mathrm{CO}_{2}$ fluxes in dense urban cores, and (2) to attempt to validate the measured fluxes by comparing them with an inventory based assessment of vehicle emissions. 


\section{The Eddy Covariance Method}

In this chapter, the equations and measurement techniques for vertical fluxes of heat and $\mathrm{CO}_{2}$ are developed. The basic equations for fluxes are obtained from Reynolds averaging and reduced to one term by assuming zero density fluctuations and zero mean vertical velocity. Eddy covariance sensors, sensor requirements, and operating principles are described. The nine-step, iterative processing of raw data to determine fluxes is explained.

\subsection{Eddy Covariance Theory}

The derivation of the eddy covariance equations begins with the equation for vertical flux,

$$
F=\overline{\rho_{a} W S}
$$

Where $\rho_{a}$ is air density, $w$ is vertical velocity, and $s$ is the concentration ratio $\rho_{c} / \rho_{a}$ of the measured variable $c$. Applying Reynolds averaging to Eq. (5) gives

$$
F=\overline{\left(\overline{\rho_{a}}+\rho_{a}^{\prime}\right)\left(\bar{w}+w^{\prime}\right)\left(\bar{s}+s^{\prime}\right)}
$$

where the overbars and primes represent averages and fluctuations, respectively. Multiplying through the right hand side generates eight components:

$$
F=\underbrace{\overline{\overline{\rho_{a} \bar{w} \bar{s}}}}_{I}+\underbrace{\overline{\overline{\rho_{a} \bar{w} s^{\prime}}}}_{I I}+\underbrace{\overline{\overline{\rho_{a}} w^{\prime} \bar{s}}}_{I I I}+\underbrace{\overline{\overline{\rho_{a}} w^{\prime} s^{\prime}}}_{I V}+\underbrace{\overline{\rho_{a}^{\prime} \bar{w} \bar{s}}}_{V}+\underbrace{\overline{\rho_{a}^{\prime} \bar{w} s^{\prime}}}_{V I}+\underbrace{\overline{\rho_{a}^{\prime} w^{\prime} \bar{s}}}_{V I I}+\underbrace{\overline{\rho_{a}^{\prime} w^{\prime} s^{\prime}}}_{V I I I}
$$

Components $I I, I I I$, and $V$ can be eliminated by the averaging rules, i.e. the average of a fluctuation is zero. Two major assumptions are used to eliminate four of the remaining 
five terms. First, the fluctuation of air density is assumed to be zero, eliminating terms VI, VII, and VIII. Second, the mean vertical wind speed is assumed to be zero, eliminating term $I$. The final flux equation becomes:

$$
F \approx \overline{\rho_{a}} \overline{w^{\prime} s^{\prime}}
$$

Eddy covariance measurement systems do not measure $s^{\prime}$ directly, but instead measure partial density $\rho_{c}$ in units of mass per volume. In the case of heat fluxes there are additional factors in the calculations. For sensible heat, the heat capacity of dry air must be applied to the covariance of vertical velocity and temperature. For latent heat, the latent heat of vaporization must be applied. Equation (8) is therefore modified to yield the fluxes of sensible heat, latent heat, and $\mathrm{CO}_{2}$ from the measured quantities:

$$
\begin{gathered}
F_{H}=\overline{\rho_{a}} C_{p} \overline{w^{\prime} T^{\prime}}, \\
F_{L E}=\lambda_{v} \overline{w^{\prime} \rho_{v}^{\prime}} \\
F_{C}=\overline{w^{\prime} \rho_{C}^{\prime}}
\end{gathered}
$$

where $C_{p}$ is the heat capacity of air, $T$ is temperature, $\lambda_{v}$ is latent heat of vaporization, $\rho_{v}$ is the partial density of water vapor, and $\rho_{C}$ is the partial density of $\mathrm{CO}_{2}$.

It is important to justify the assumptions made in deriving Eq. (8). Fluctuations in air density can be caused by fluctuations in pressure, temperature, and humidity. Fluctuations in pressure are small except in cases of high winds and/or steep terrain, and generally can be neglected (Lee et al., 2004). Temperature and humidity fluctuations can have large effects on latent heat and $\mathrm{CO}_{2}$ fluxes if, as in most systems, water vapor and $\mathrm{CO}_{2}$ are measured as densities, as opposed to molar concentrations 
(Webb et al., 1980). Webb et al. (1980) showed that if the temperature and humidity fluctuations are known, the correct latent heat and component mass fluxes (such as $\mathrm{CO}_{2}$ ) can be computed as:

$$
\begin{gathered}
F_{L E}=(1+\mu \sigma)\left[\overline{w^{\prime} \rho_{v}^{\prime}}+\left(\overline{\frac{\rho_{v}}{\bar{T}}}\right) \overline{w^{\prime} T^{\prime}}\right] \\
F_{C}=\overline{w^{\prime} \rho_{c}^{\prime}}+\mu\left(\frac{\overline{\rho_{c}}}{\overline{\rho_{a}}}\right) \overline{w^{\prime} \rho_{v}^{\prime}}+(1+\mu \sigma)\left(\overline{\frac{\rho_{c}}{\bar{T}}}\right) \overline{w^{\prime} T^{\prime}}
\end{gathered}
$$

In these equations $\mu$ is the molar mass ratio of dry air to water vapor $\left(M_{a} / M_{v}\right)$, and $\sigma$ is the ratio of mean water vapor density to dry air density $\left(\overline{\rho_{v}} / \rho_{a}\right)$. These corrections assume all constituents are ideal gases, and also relies on a binomial expansion where terms of scale 0.01 and smaller are neglected. They are generally known as the WPL corrections, after the authors of Webb et al. (1980).

Inside the RSL, local effects such as recirculation and wall shear stress can create both positive and negative mean vertical velocities. Above the RSL, where eddy covariance measurements are traditionally made, it is intuitive that the average velocity normal to terrain with no vertical momentum sources or sinks is zero. This assumption is enforced by rotating the measured coordinate system so that $\bar{w}=0$, effectively rotating the top plane of the control volume about the sensor location. Because this is accomplished in postprocessing, the two established methods for performing this coordinate rotation are discussed in Section 2.3. One of these methods allows for nonzero $\bar{w}$, though determining the correct value remains problematic (Lee et al., 2004). 
Three additional assumptions are implicit in the use of Reynolds averaging to calculate turbulent fluxes: Ergodicity, stationarity, and homogeneity. Ideally, the statistical measurements of turbulent flows would be obtained with an ensemble of many realizations under identical conditions (Kaimal \& Finnigan, 1994). This is not feasible for atmospheric flows, so time averages must be used. The ergodic assumption states that the time average of a measured quantity converges to the average of an ensemble of similar experiments as the averaging time increases (Tennekes \& Lumley, 1972). Hence time averages can be used to represent ensemble averages if the signal is ergodic. For this to be true, the turbulence statistics must be stationary over the measurement period. A stationary process is one that is statistically independent of time. This is perhaps best described by Taylor's hypothesis, also known as the frozen turbulence approximation. Taylor's hypothesis states that advection of a field of turbulence past a point is due solely to mean flow, so that the fundamental properties of the turbulence field remain the same as it moves through the point. This is true if the mean velocity $\bar{u}$ is much larger than the fluctuating velocity $u^{\prime}$. Statistical tests for stationarity are discussed in Section 2.3. Homogeneity is the spatial equivalent of stationarity, requiring that the statistics of a process are invariant under changes in location. In complex urban terrain, this is clearly not achievable. If the precise source area, or footprint, contributing to the point measurements is known, homogeneity is not required. Unfortunately, standard footprint models such as that of Gash (1986), or 
more recently Hsieh (2000), are invalid in complex urban terrain. As an alternative, the footprint in this study will be determined from a computational fluid dynamics model.

Another important concept to the eddy covariance technique is that of spectral and cospectral representations of turbulent flows. Any function of time $g(t)$, for example a time series of a meteorological variable, can be represented as a function of frequency by applying the Fourier transform:

$$
G(\omega)=\frac{1}{\sqrt{2 \pi}} \int_{-\infty}^{\infty} g(t) e^{-i \omega t} d t
$$

where $\omega$ is the angular frequency. This frequency representation is known as the spectrum of function $g(t)$. In atmospheric studies, this transform is most commonly applied to the turbulent kinetic energy of the wind. Physically, this represents the energy contribution from eddies of different frequencies and physical size. The Fourier transform of two functions of time is known as the cross spectrum, the real part of which is called the cospectrum (Foken, 2008a). Physically, the cospectra of $w^{\prime} \chi^{\prime}$, where $\chi$ is temperature, humidity, or $\mathrm{CO}_{2}$ concentration, show the relative contributions from different frequencies to the measured fluxes. This is important in eddy covariance studies for two reasons. The first is that established spectral and cospectral models developed through rigorous measurements can be compared. The second is that eddy covariance instruments do not have a uniform response over all frequencies. Transforming measurements into the frequency domain makes it possible to correct errors due to frequency response. These corrections are discussed in detail in Section 2.3. 


\subsection{Eddy Covariance Instruments}

A basic eddy covariance system consists of a sonic anemometer, a gas analyzer, and a data storage device. Common additional sensors include fine-wire thermocouples, RTD or PRT temperature detectors, and capacitive relative humidity sensors.

Sonic anemometers (Figure 6(A)) measure three-dimensional wind velocities and sonic temperature. This is accomplished by measuring time-of-flight of sonic pulses between three sets of non-orthogonal transducers, then transforming the resulting velocities into an orthogonal coordinate system (Campbell Scientific, Inc., 2007). Sonic temperature is air temperature derived from the speed of sound in air. This measurement is possible because the speed of sound $C_{S}$ is a function of air temperature and humidity:

$$
C_{S}^{2}=\gamma_{D} R_{D} T(1+0.51 q)
$$

where $\gamma_{D}$ is the ratio of specific heat of dry air at constant pressure to that at constant volume, $R_{D}$ is the gas constant for dry air, and $q$ is the specific humidity defined as the ratio of mass of water vapor to mass of dry air (Campbell Scientific, Inc., 2007). Sonic temperature measurements can be used to measure sensible heat flux, but humidity must be known to correct the flux in postprocessing.

Gas analyzers (Figure 6(B)) measure partial densities of gases, in this case water vapor and carbon dioxide, as well as total atmospheric pressure. In most $\mathrm{H}_{2} \mathrm{O} / \mathrm{CO}_{2}$ gas analyzers these quantities are measured using infrared absorption. This technique 


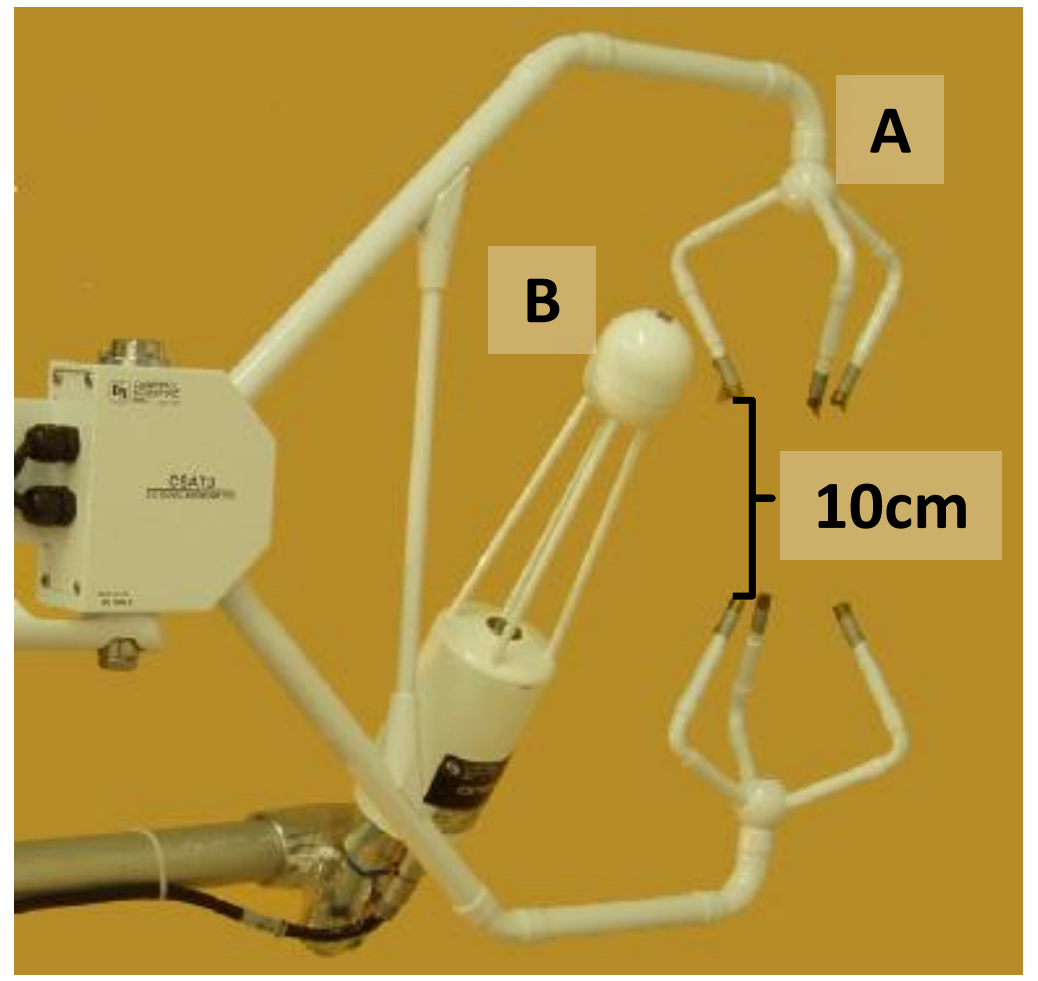

Figure 6: Eddy covariance instruments. A Campbell Scientific CSAT3 sonic anemometer (A) mounted in front of a LI-COR LI-7500 open path gas analyzer (B).

sends an infrared (IR) beam across a path of known length and measures the attenuation. The gas concentration can then be determined using well known absorption characteristics (LI-COR, Inc., 2004). Infrared gas analyzers are split into two form factors: Open path and closed path. In open path sensors, such as in Figure 6, the infrared beam path is placed directly in the atmosphere. In closed path systems, gas is drawn through a tube to an enclosed infrared sensor. Open path sensors have the advantages of lower power consumption, less frequent calibration, and short time delays between sonic anemometer measurements and gas measurements. Closed path 
sensors require more corrections in postprocessing due to the time delay from the tube, but unlike the open path sensors they can collect data during rain events.

The high speed measurements necessary for eddy flux measurements generate a large amount of data, approximately $1 \mathrm{~GB}$ per month for a single system. In the past, this meant either limiting eddy covariance studies to short durations or using running averages or other statistical techniques to reduce the volume of data recorded (Aubinet et al., 2000). Currently, several models of digital datalogger with onboard flash memory or network outputs are readily available. Data storage and transfer with these devices is straightforward.

Fine-wire thermocouples are sometimes used to take direct, high speed measurements of air temperature. This eliminates the need for sonic temperature corrections, and is necessary if high speed humidity measurements are not available. Slow response sensors such as RTD or PRT temperature sensors and capacitive RH sensors are used for verification and postprocessing corrections.

The sonic anemometer and gas analyzer must meet certain requirements for speed, sensitivity, and structure in order to provide accurate data. First, the measurements must be fast enough that they capture the smallest eddies that contribute to the turbulent fluxes. In Figure 7, the spectral distribution of turbulent energy in the atmosphere can be seen to fall off at frequencies above $10 \mathrm{~Hz}$. To avoid aliasing, the instruments should sample at double this frequency, $20 \mathrm{~Hz}$. Sensitivity requirements for measuring means and fluctuations are $\pm 0.05 \mathrm{~m} / \mathrm{s}$ for wind velocity, $\pm 0.05^{\circ} \mathrm{C}$ for 


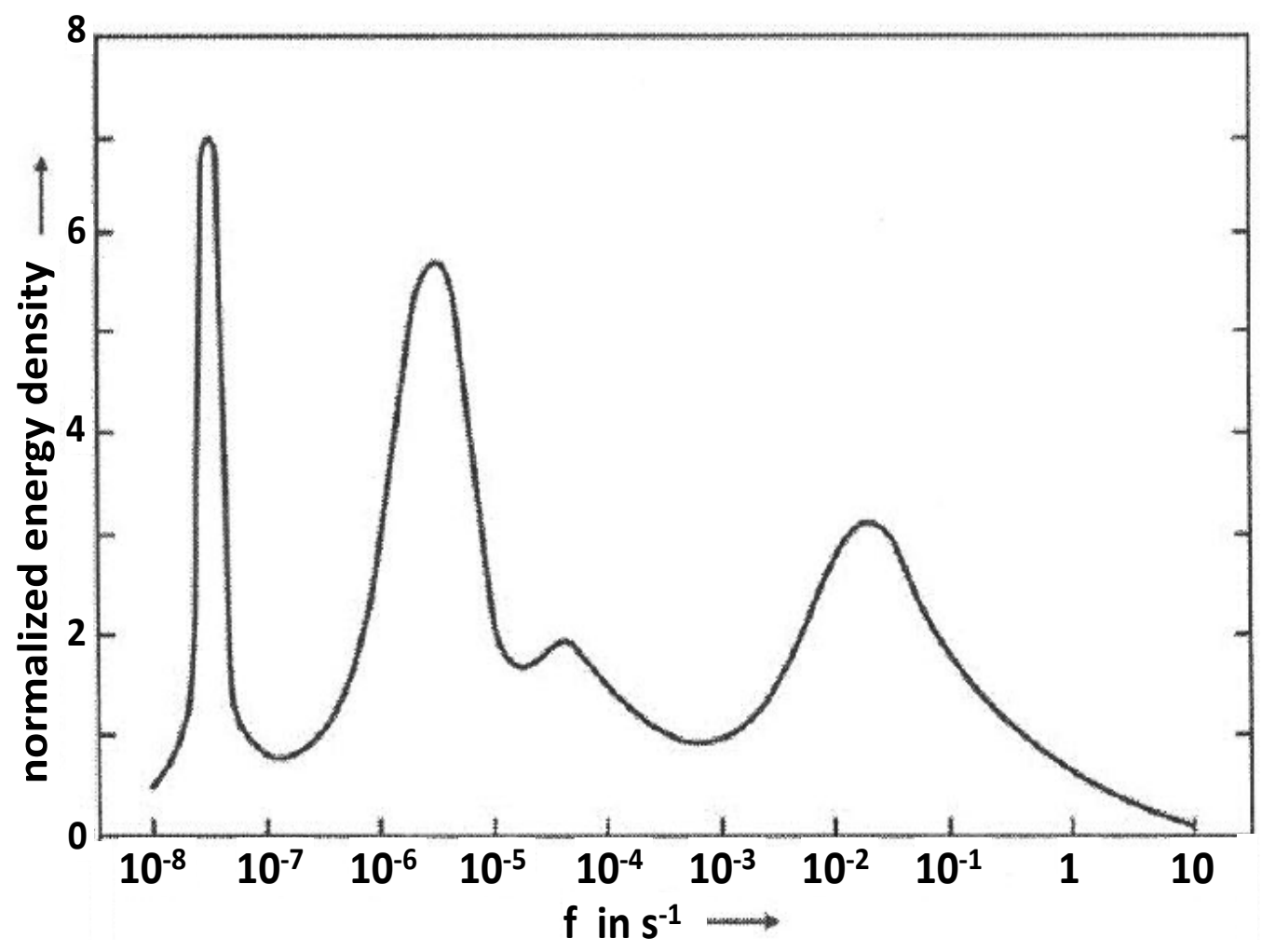

Figure 7: Atmospheric turbulence spectrum from Foken (2008a).

temperature, and \pm 0.05 mbar $\left(0.037 \mathrm{~g} / \mathrm{m}^{3}\right)$ for humidity (Kaimal \& Finnigan, 1994). In terms of structure, the instruments must be constructed such that they do not distort the flow. In practice, instruments cannot be built that eliminate flow distortion in all directions. Care must be taken when selecting a site to determine the prevailing wind direction in advance so that the sensors can be appropriately oriented. The sensing path must also be short enough that it does not average small eddies. The smallest meaningful turbulent length scale is the Kolmogorov scale, which represents the length scale where the kinetic energy of eddies is dissipated by transformation into thermal energy. The largest important length scale is the integral scale, which represents the 
scale where kinetic energy from the mean flow is transferred to turbulent eddies. Approximate values for these scales in atmospheric flows are $0.001 \mathrm{~m}$ for the Kolmogorov scale and $10 \mathrm{~m}$ to $500 \mathrm{~m}$ for the integral scale (Foken, 2008a). Sonic anemometers used in eddy covariance measurements generally have a path length on the order of $0.1 \mathrm{~m}$, two orders of magnitude larger than the Kolmogorov scale. Sensors of this size can only resolve scales down to $0.31 \mathrm{~m}$ (George, 2002), so in practice the smallest important scales are never resolved. Instead, turbulent kinetic energy spectrum between the integral and Kolmogorov scales is assumed to follow the "-5/3 law", which states that turbulent kinetic energy is a function of wavenumber raised to the $-5 / 3$ power. This assumption can be used to correct the attenuation due to pathlength averaging (Foken, 2008a).

\subsection{Processing}

Once collected, raw turbulence data must be processed and corrected to determine atmospheric fluxes. Figure 8 shows a standard processing procedure, with a detailed explanation below.

1. Despiking: Data spikes in eddy covariance systems may be caused by random electronic spikes in the instruments or by precipitation collecting on sonic transducers or the window of the gas analyzer (Vickers \& Mahrt, 1997). Most despiking routines are based on that of $\mathrm{H} \varnothing \mathrm{jstrup}$ (1993). This method computes the mean and standard deviation for a series of moving windows of length $L_{1}$ values. 


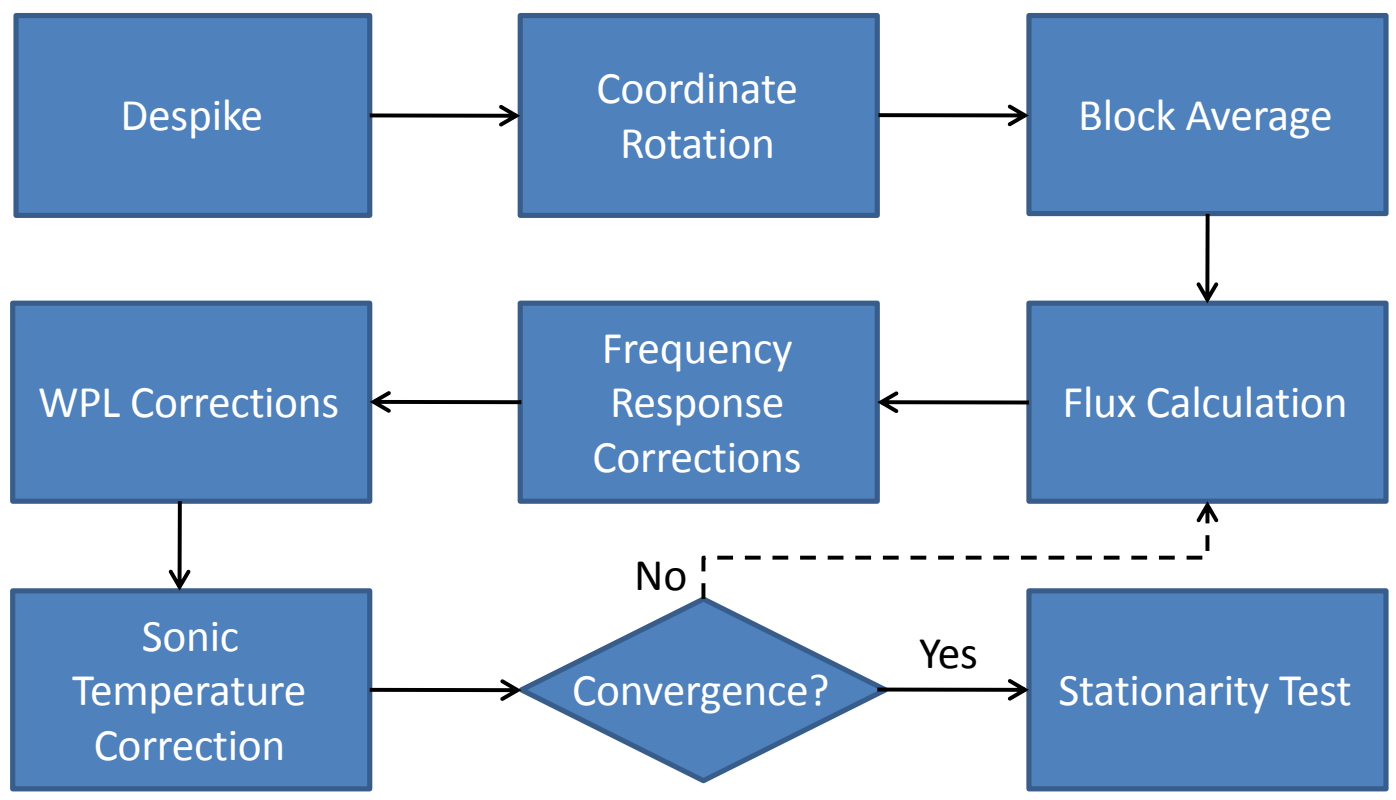

Figure 8: Processing procedure

The window is stepped one value at a time. Any value exceeding $Q$ standard deviations is considered a spike, unless four or more consecutive points are detected, in which case the "spike" is considered to be physical. Spikes can then be removed from the time series or replaced by linear interpolation. The window length $L_{1}$ is generally taken to be 10 (Højstrup, 1993); (Mauder \& Foken, 2004). Vickers and Mahrt (1997) use a somewhat arbitrary $Q$ of 3.5 standard deviations,

2. based on visual inspection of spike filled records and on tests that evaluate the sensitivity of the change in calculated fluxes before and after spikes are removed. Mauder and Foken (2004) use a $Q$ of 5.5, which must also be taken as somewhat arbitrary as no physical or experimental validation is given.

3. Coordinate Rotation: As discussed in section 2.1, there are two methods for rotating the coordinate system and enforcing the assumption that $\bar{w}=0$. The first method, 
originally proposed by Tanner and Thurtell (1969), simply performs a double rotation for each averaging period. First the $x-y$ plane is rotated at angle $\alpha$ about the $z$-axis such that:

$$
\alpha=\tan ^{-1}\left(\frac{\bar{v}}{\bar{u}}\right)
$$

The new $x-z$ plane is then rotated at angle $\beta$ such that:

$$
\beta=\tan ^{-1}\left(\frac{\bar{w}}{\sqrt{\bar{u}^{2}+\bar{v}^{2}}}\right)
$$

The rotations are illustrated in Figure 9. After the two rotations, $\bar{v}=\bar{w}=0$. A third rotation of angle $\gamma$ should be performed about the new $\mathrm{x}$-axis so that the roll angle of the flux plane correctly represents the vertical covariances $\overline{w^{\prime} \chi^{\prime}}$. This is generally accomplished by assuming that $\overline{u^{\prime} v^{\prime}}=\overline{v^{\prime} w^{\prime}}=0$. The third rotation has rarely been used in practice because it frequently yields unstable or unphysical angles for
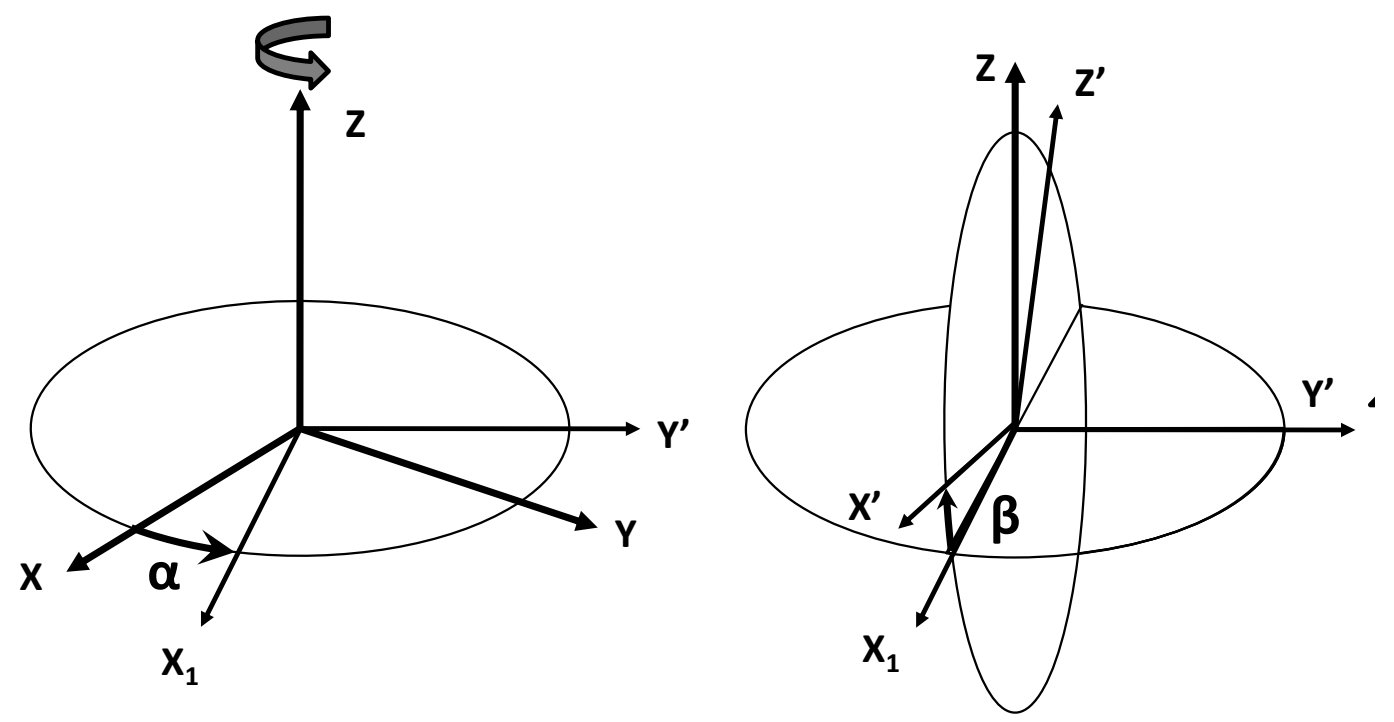

Figure 9: The two-rotation method in Eqs. (16) and (17). The new coordinate axes are primed, intermediate axes have subscripts. 
$\gamma$. Finnigan (2004) demonstrated that this was the result of a closure problem. An alternative method, proposed by both Paw U et al. (2000) and Wilczak (2001), eliminates this closure problem. This method, known as the "planar fit" method, simultaneously performs the $\beta$ and $\gamma$ rotations as a matrix operation. This is accomplished by multiplying the measured velocity vector by the partial rotation matrix $\boldsymbol{P}$ of Eq. (18), placing the z-axis perpendicular to the mean streamlines.

$$
\boldsymbol{P}=\left[\begin{array}{ccc}
\cos \beta & 0 & -\sin \beta \\
0 & 1 & 0 \\
\sin \beta & 0 & \cos \beta
\end{array}\right]\left[\begin{array}{ccc}
1 & 0 & 0 \\
0 & \cos \gamma & \sin \gamma \\
0 & -\sin \gamma & \cos \gamma
\end{array}\right]
$$

The coefficients of matrix $P$ are determined directly by a linear regression of halfhour means to create an $x-y$ plane that is parallel to the long-term mean streamlines (Figure 10). Details can be found in Wilczak (2001). Once this plane has been defined, the coordinate system is rotated angle $\alpha$ about the new z-axis to set $\bar{v}=0$ for each averaging period. While data quality is higher for the planar fit method than for the double-rotation method (Lee et al., 2004), there are practical difficulties in applying it. The first is that it requires a large data set, on the order of weeks, to calculate an appropriate $\boldsymbol{P}$ matrix. During this period, long term changes such as seasonal variations and sensor calibration drift can have a disproportionate effect on the measurement of fluctuations in temperature and concentrations (Finnigan et al., 2003). The second issue is the necessity for multiple $\boldsymbol{P}$ matrices in cases where the fetch is not uniform for all wind vectors. In these cases, uniform sectors must be identified and a matrix must be determined for each relevant sector. 


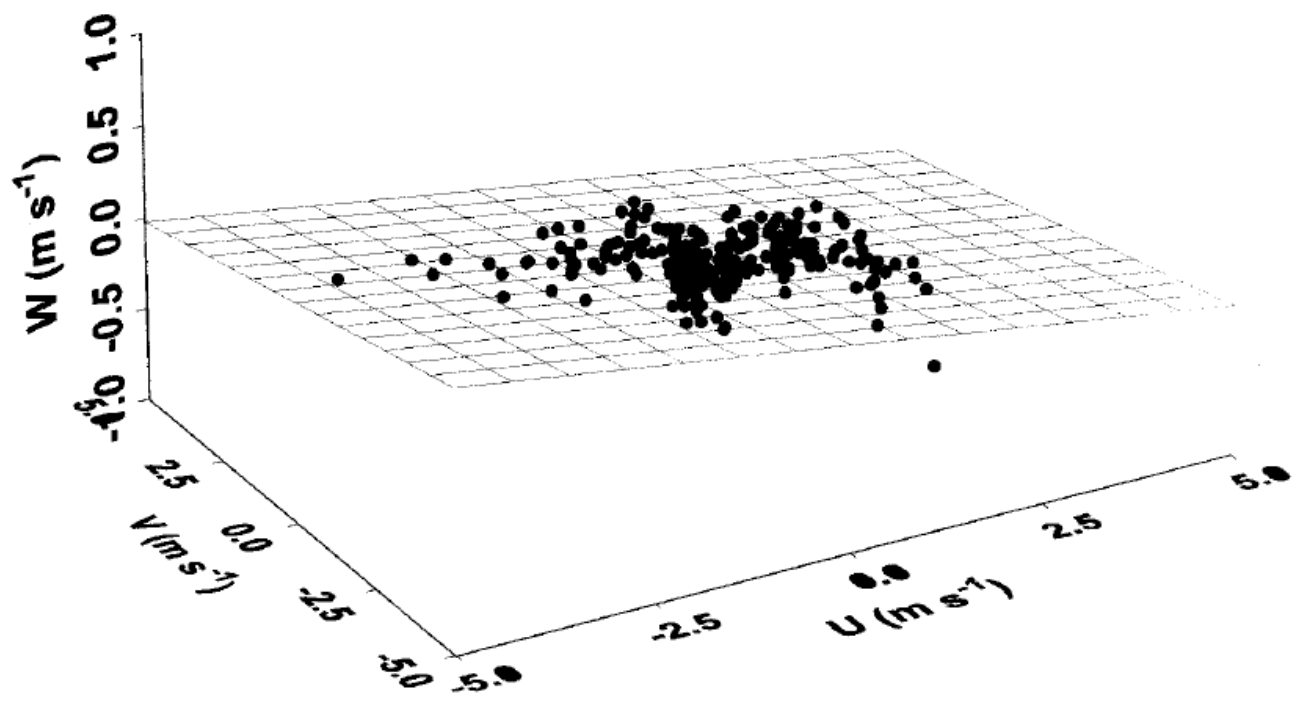

Figure 10: Planar fit example from Paw U et al. (2000). Each data point represents a set of half-hour mean velocities.

4. Block Averaging: In order to calculate the fluctuating quantities, the means must be removed from the raw data. Because the means are calculated in the time domain, as opposed to true ensemble means, the choice of averaging period affects the calculated fluxes. Shorter averaging periods have the effect of a high-pass filter, removing the contribution from larger, low frequency eddies. Longer averaging periods are at greater risk of violating the stationarity criteria (Foken, 2008a). Block averages of 30 minutes are most common in eddy flux studies, but this has been shown to underestimate the fluxes in some sites by $4-17 \%$ (Sakai et al., 2001); (Finnigan et al., 2003). A more rigorous method of determining an appropriate averaging period is to use ogive plots that integrate under the cospectral curve of each flux and show the cumulative contribution of eddies of decreasing frequency to the total transport (Lee et al., 2004). If the ogive curves reach an asymptote as the 
HOURLY OGIVES, HEAT FLUX, 10 MAY 1998, $396 \mathrm{~m}$

a) $\widehat{T}$

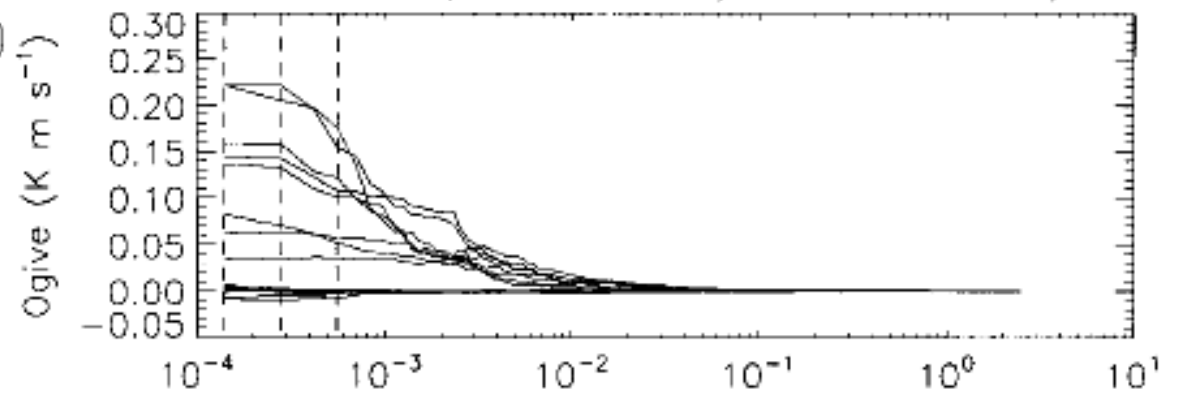

$122 \mathrm{~m}$

b)
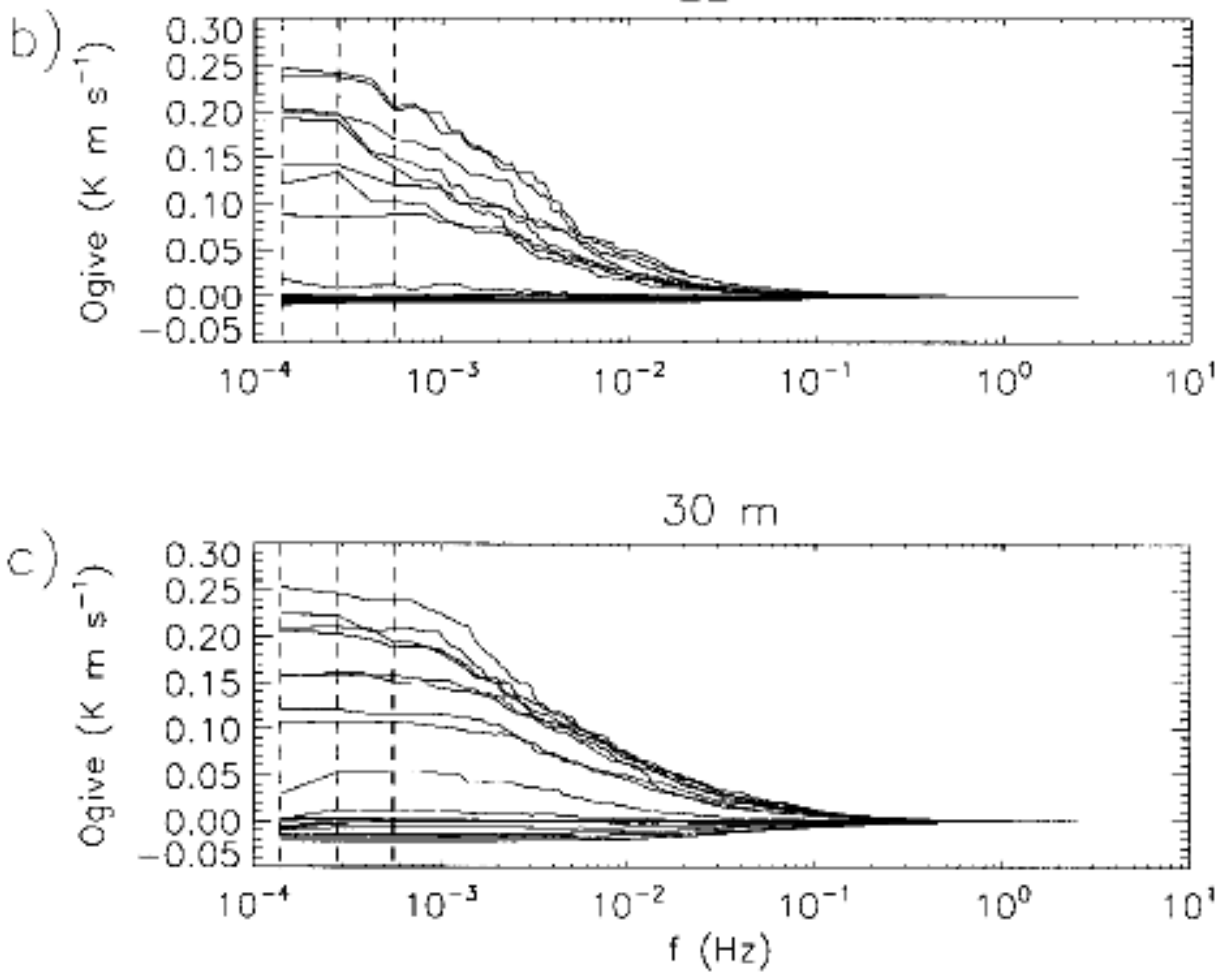

Figure 11: Ogives for sensible heat flux at measurement heights of a) $396 \mathrm{~m}$, b) $122 \mathrm{~m}$, and c) $30 \mathrm{~m}$. The dashed vertical lines correspond to averaging periods of $2 \mathrm{~h}, 1 \mathrm{~h}$, and $0.5 \mathrm{~h}$, from left to right. Lines in each panel represent 2 -hour sample periods centered on each hour of the day. (Berger et al., 2001) 
averaging period is increased, the asymptotes indicate the lower frequency limit for flux contributions. Figure 11 is an example of ogive plots for heat flux measurements taken at different heights over a forest canopy. The $x$-axis represents the period of the cospectrum of $\overline{w^{\prime} T^{\prime}}$. The cumulative contribution of progressively larger eddies is shown on the $y$-axis as one moves from right to left on the $x$-axis. These plots indicate that a 30-minute averaging interval is appropriate for low-level measurements, but as measurement height increases the averaging period should increase as well.

5. Flux Calculations: Preliminary sensible, latent, and $\mathrm{CO}_{2}$ fluxes are calculated using Eqs. (9), (10), and (11), respectively. Unless a fine wire thermocouple is used for temperature measurements, sensible heat flux (Eq. (9)) is calculated using the sonic temperature, $T_{S}$. Because the speed of sound is dependent on humidity in addition to temperature, heat flux values calculated with $T_{S}$ must be corrected for humidity fluctuations. This correction is discussed in detail in processing step 7.

6. Frequency Response Corrections: While modern eddy covariance sensors sample quickly enough to capture the contributions of the smallest eddies, physical limitations on the size of the sampling volumes and separation between the sensors lead to underestimation of the high frequency contributions (Figure 12). Methods for correcting the spectral loss can be divided into two categories: Transfer function methods and in situ methods. 


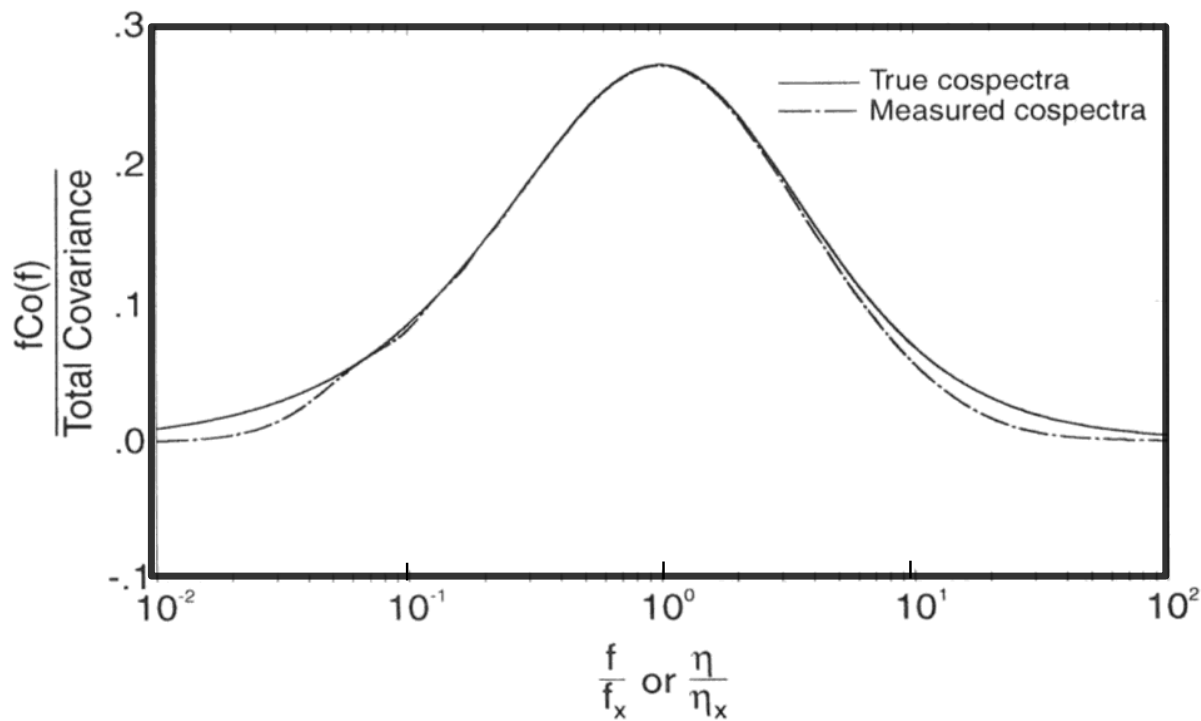

Figure 12: A comparison of an idealized atmospheric cospectrum versus their measurement by an eddy covariance system (Lee et al., 2004). Attenuation at higher frequencies is caused by sensor separation and line averaging. Low frequency attenuation is a consequence of block averaging. Here $f$ is frequency, $f C o(f)$ is the frequency weighted covariance $\overline{w^{\prime} \chi^{\prime}}$ as a function of $f, f_{x}$ is the frequency at which $f(\mathrm{Co})$ reaches its maximum value, and $\eta$ and $\eta_{x}$ are the respective nondimensionalized forms of $f$ and $f_{x}$.

Transfer function methods use knowledge of idealized atmospheric turbulence spectra and physical instrument characteristics to correct the measured fluxes. This is accomplished by convolution of the frequency-dependent response functions of the instruments with the co-spectral distribution functions associated with atmospheric turbulent fluxes (Moore, 1986). The general mathematical form is:

$$
\frac{\left(\overline{w^{\prime} \chi^{\prime}}\right)_{m}}{\overline{w^{\prime} \chi^{\prime}}}=\frac{\int_{0}^{\infty} T(f) C o_{w \chi}(f) d f}{\int_{0}^{\infty} C o_{w \chi}(f) d f}
$$

where $\left(\overline{w^{\prime} \chi^{\prime}}\right)_{m}$ is the measured covariance of scalar $\chi, f$ is frequency, $T(f)=$ $\prod_{i=1}^{N} T_{i}(f)$ is the product of all of the appropriate individual transfer functions, and 
$\mathrm{Co}_{w \chi}(f)$ is the cospectrum associated with the transport of scalar $\chi$. Moore (1986) used simplified transfer functions for line averaging of vertical wind velocity $w$, line averaging of scalars, and sensor separation. Massman (2000 \& 2001) instead models the high frequency transfer functions as first-order low pass filters, after Horst (1997). The general form of this transfer function is

$$
T_{c}(f)=\left[1+\left(2 \pi f \tau_{c}\right)^{2}\right]^{-1}
$$

where $\tau_{c}$ is the time constant associated with a given instrument or spatial separation. Recent treatments of this method, including Massman (2000 \& 2001), also include a transfer function for low frequency attenuation due to block averaging:

$$
T_{b}(f)=\left[1-\frac{\sin ^{2}\left(\pi f B_{t}\right)}{\left(\pi f B_{t}\right)^{2}}\right]
$$

where $B_{t}$ is the block averaging period (Lee et al., 2004). Transfer function methods also require a cospectral model $C o_{w \chi}(f)$. Unfortunately, most models, such as those given in Moore (1986) and Horst (1997), are based on the measurements of Kaimal et. al (1972). These models are unsuitable for use in complex terrain for several reasons. First, the measurements were taken over a flat, uniform grassland that yielded a smooth, continuous cospectral curve. Most observed cospectra in other locations display significant variability (Lee et al., 2004). Second, these models are dependent on atmospheric stability $z_{m} / L$, where $L$ is the Obukhov length. As such, they assume Monin-Obukhov similarity, which requires both stationarity and 
horizontal homogeneity (Horst, 1997). In addition, these models are based on cospectra for $\overline{w^{\prime} T^{\prime}}$, hence cospectral similarity between $\overline{w^{\prime} T^{\prime}}$ and $\overline{w^{\prime} \rho_{v}^{\prime}}$ or $\overline{w^{\prime} \rho_{C}^{\prime}}$ must be assumed if they are used to correct latent heat or $\mathrm{CO}_{2}$ flux. In homogeneous terrain where the sources and sinks of heat and $\mathrm{CO}_{2}$ are collocated or evenly distributed, this assumption can be justified. In complex urban terrain, where point and line sources (e.g. buildings, roads) are the norm, this assumption is not valid.

In situ methods eliminate the need for cospectral models by taking the ratio of a reference flux that is assumed to have no high frequency attenuation (usually $\overline{w^{\prime} T_{s}^{\prime}}$ ) to an attenuated flux. This ratio is then used as a correction factor for a cospectrally similar measured flux. Though the cospectral models are no longer necessary, cospectral similarity between heat and gas fluxes must still be assumed. In addition, high frequency corrections to the reference flux are not applied. Lastly, in situ methods must be calibrated to the individual site and system that the corrections are applied to, which introduces additional uncertainties (Lee et al., 2004).

7. WPL Corrections: Latent heat flux $F_{L E}$ and $\mathrm{CO}_{2}$ flux $F_{C}$ are corrected according to Eqs. (12) and (13), respectively, as discussed in Section 2.1.

8. Sonic Temperature Correction: Sonic anemometers derive temperature measurements from the speed of sound in air, and as a consequence the measurements are affected by crosswind momentum and changes in humidity (Schotanus et al., 1983). Crosswind momentum corrections are calculated internally 
by all modern sonic anemometers and are not considered here. Corrections for humidity fluctuations are made by substituting the following into Eq. (9):

$$
\overline{w^{\prime} T^{\prime}}=\overline{w^{\prime} T_{s}{ }^{\prime}}-0.51 \cdot \bar{T} \cdot \overline{w^{\prime} q^{\prime}}
$$

where $q^{\prime}$ is the specific humidity fluctuation and $\bar{T}$ is the average air temperature (Mauder \& Foken, 2004). Because $T_{S}$ deviates from the true temperature, $\bar{T}$ is generally taken from a slow response temperature sensor such as an RTD, as opposed to an average of $T_{s}$.

9. Convergence Test: It can be seen in steps 5, 6, and 7 that the sensible and latent heat fluxes are interdependent, and that $\mathrm{CO}_{2}$ fluxes are dependent on moisture fluctuations. These fluxes cannot be calculated simultaneously without undesirable simplifications, so steps 4-6 are typically iterated until the difference in fluxes between iterations is $0.01 \%$ or less (Mauder \& Foken, 2004).

10. Stationarity Test: Stationarity is tested by comparing the covariances of the halfhour block average with those of smaller periods within the block average, based on the method of Foken and Wichura (1996). The measured time series is divided into $M=6$ intervals of 5 minutes. The difference between the covariances, $R N_{c o v}$, is calculated as:

$$
R N_{\text {cov }}=\left|\frac{\frac{1}{M} \overline{w^{\prime} \chi^{\prime}{ }_{5 \mathrm{~min}}}-\overline{w^{\prime} \chi^{\prime}{ }_{30 \mathrm{~min}}}}{\overline{w^{\prime} \chi^{\prime} 30 \mathrm{~min}}}\right|
$$

Blocks with $R N_{\text {cov }}<30 \%$ are considered stationary. $R N_{c o v}$ is typically calculated 
for temperature, water vapor, and $\mathrm{CO}_{2}$ covariances with vertical wind velocity $W$. It is not used as a filter criterion during postprocessing, but rather as a flag on the quality of a given measurement. While the $30 \%$ value appears to be arbitrary in terms of the physical system, it is based on long experience (Mauder \& Foken, 2004), and agrees well with other quality parameters (Foken \& Wichura, 1996). 


\section{Method}

This chapter lays out the site, instrumentation, and processing procedure used in this study. Sensors are placed in the RSL of Portland, Oregon's urban center. A standard Campbell Scientific eddy covariance system with an open path gas analyzer was used. Data processing was performed by EdiRe, a program developed at the university of Edinburgh. Data was processed according to the steps listed in Section 2.3, with the exception that frequency response corrections and the iterative process are omitted.

\subsection{Site}

The instrument package was located at the south end of the urban center of Portland, Oregon (Figure 13), at the corner of southwest Harrison Street and 4th Avenue. The urban center occupies and area of roughly $4.5 \mathrm{~km}^{2}$. The instruments were mounted on a 4-meter steel tower placed on the roof of Portland State University's Fourth Avenue Building (FAB). The roof is 11 meters above street level, giving a total height of $15 \mathrm{~m}$. The site is bordered to the north by $2 \mathrm{~km}$ of tall, densely packed buildings, some exceeding $100 \mathrm{~m}$ in height. The dominant feature to the east is the Willamette river, which cuts south-to-north through the city $500 \mathrm{~m}$ east of the sensor location. To the south and west are $500 \mathrm{~m}$ of medium height and density buildings followed by I-405, a major freeway, then leading to a heavily forested hill that rises to $300 \mathrm{~m}$ elevation over $1.5 \mathrm{~km}$. 


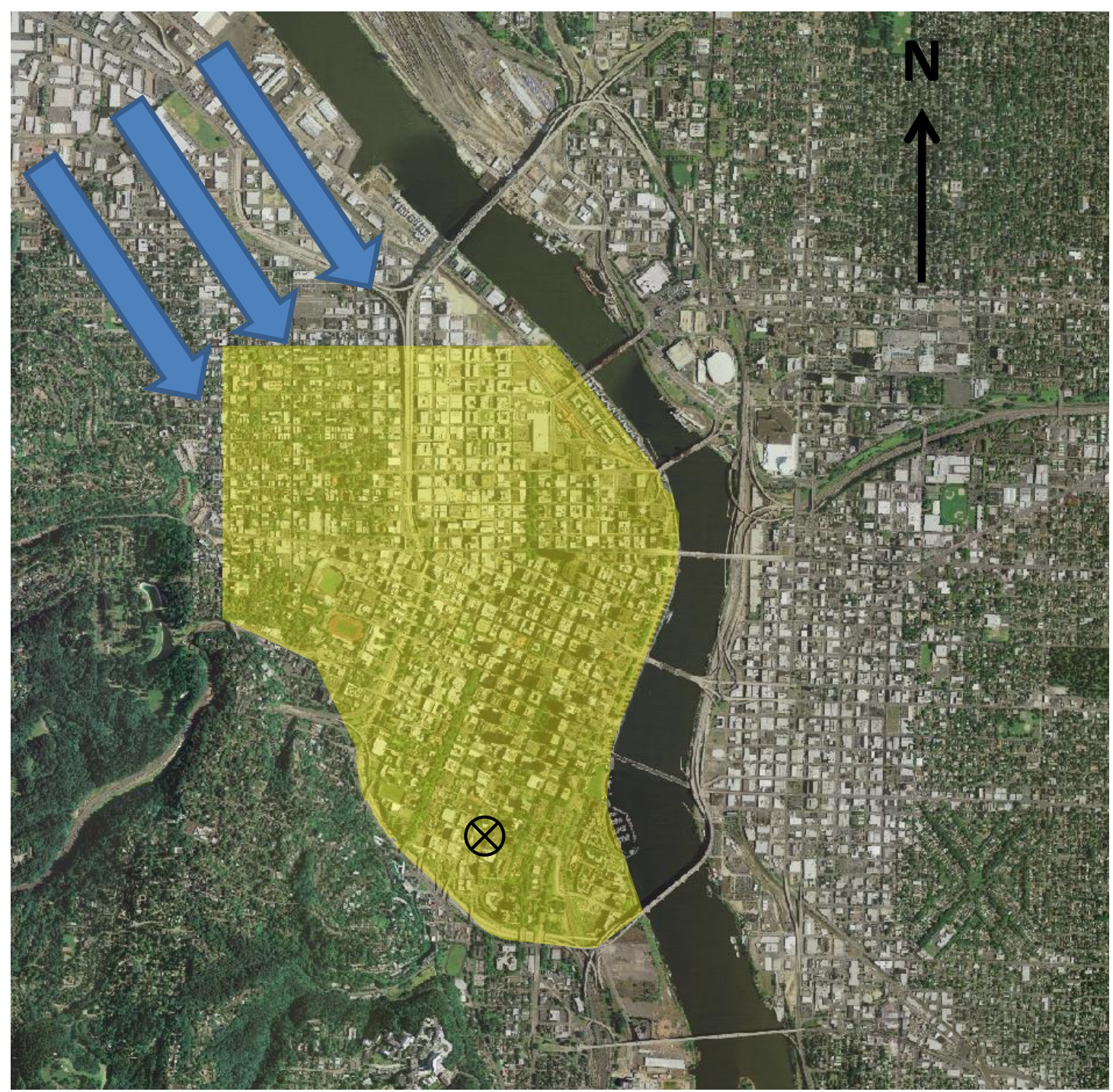

Figure 13: City Center of Portland, Oregon. The urban core is highlighted, and the sensor location is marked with a crosshair. The blue arrows represent the prevailing summer wind direction. Image courtesy of City of Portland.

The site was chosen for three reasons: Long upwind fetch in summer months, accessibility, and height above street level. Historic wind data indicates that north by northwest winds $\left(315^{\circ}-360^{\circ}\right)$ dominate the summer months, May through September. The prevailing wind shifts nearly $180^{\circ}$ in winter (November through March), coming 
primarily from the southeast, while wind vectors in the shoulder months (October and April) tend to reflect the transition between summer and winter (Oregon Climate Service, 2009). The NNW summer winds yield a fetch of 2 or more kilometers within the urban core. The building roof was easily accessible for transporting equipment, and power was available at roof level. The roof was tall enough relative to street level to place the sensors above the displacement height (given below), but not so high as to give an unreasonably long fetch. An additional consideration was the site's downwind proximity to the future location of the Oregon Sustainability Center, possibly setting the stage for construction impact measurements.

For this study, wind vectors between 10 and 190 degrees were rejected due to tall nearby buildings, equipment on the FAB roof, and source areas that were not in the area of interest. The remaining wind vectors can be divided into three zones based on upwind terrain (Figure 14). Zone 1 , from $310^{\circ}$ to $10^{\circ}$, is characterized by a $1.5+\mathrm{km}$ fetch of dense urban terrain, with a displacement height $z_{d}$ of $12.7 \mathrm{~m}$. Zone 2 , from $250^{\circ}$ to $310^{\circ}$, has between $500 \mathrm{~m}$ and $800 \mathrm{~m}$ of dense urban terrain and $z_{d}$ of $11.2 \mathrm{~m}$ leading up to the slopes of the west hills. Zone 3 , from $190^{\circ}$ to $250^{\circ}$, is more sparsely built than the other zones in its $500 \mathrm{~m}$ run to the base of the hills, with a $z_{d}$ of $3.9 \mathrm{~m}$. Displacement height for each zone was calculated using the morphometric method from Raupach (1994) as recommended in Grimmond \& Oke (1999), for the nearest 500 m of fetch. Details of this method are shown in Appendix A. 


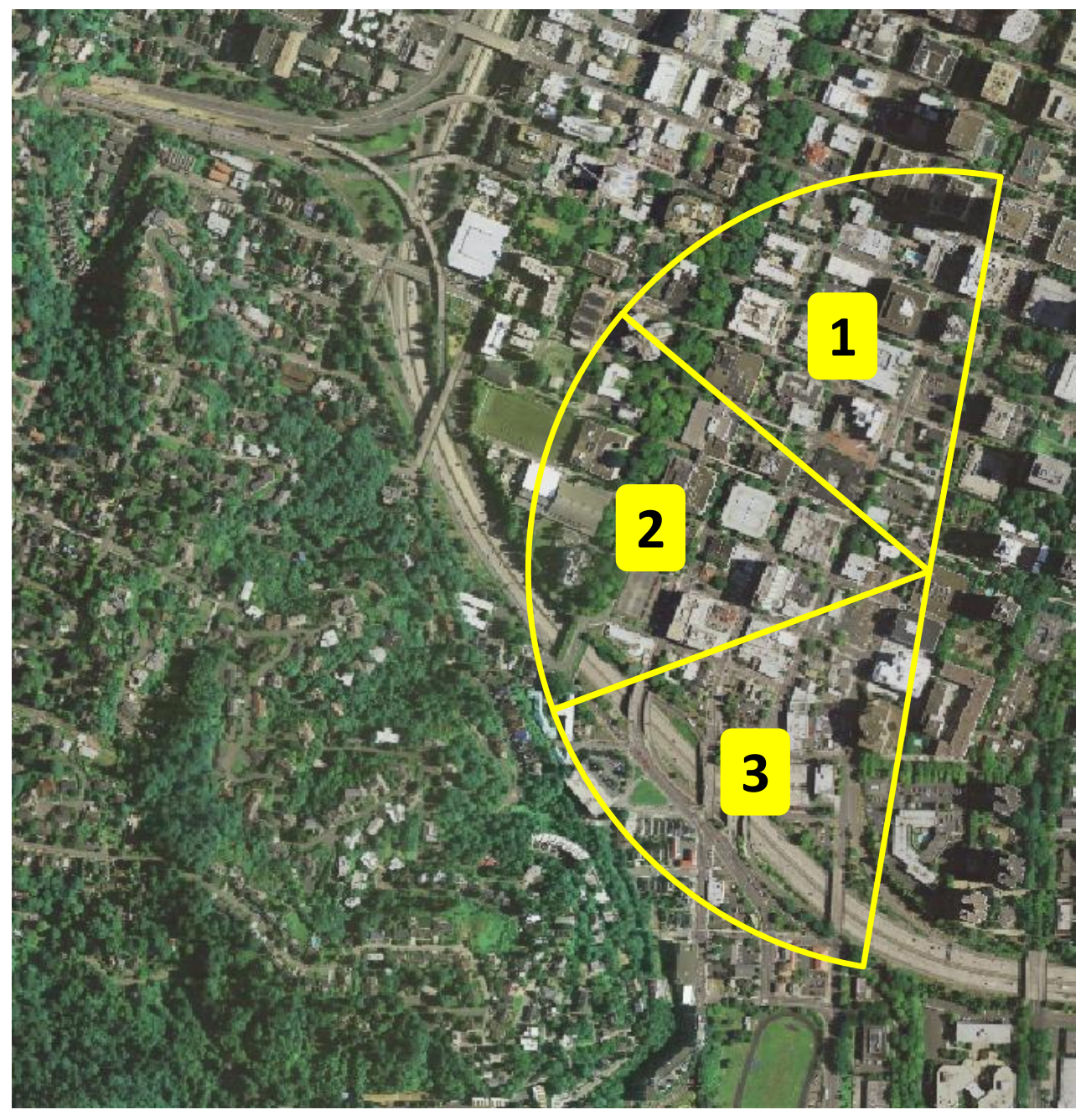

Figure 14: Accepted wind zones. Image courtesy of City of Portland

Table 1 shows generalized weather data for August, September, and October of 2009, taken from the NOAA weather station at PDX. August was somewhat evenly split between hot, sunny days, and cooler, overcast days with occasional light precipitation. September was somewhat cooler, with more frequent and voluminous rain events. October was characterized by much cooler temperatures and very regular precipitation. 
Table 1: Monthly weather for 2009

\begin{tabular}{lccccc}
\hline Month & \multicolumn{3}{c}{ Temperature $\left({ }^{\circ} \mathrm{C}\right)$} & \multicolumn{2}{c}{ Precipitation } \\
\hline & High & Average & Low & Days & Sum $(\mathrm{cm})$ \\
\cline { 2 - 6 } August & 36 & 21 & 11 & 7 & 1.93 \\
September & 34 & 19 & 8 & 14 & 6.12 \\
October & 22 & 13 & 4 & 21 & 3.05 \\
\hline
\end{tabular}

\subsection{Instrumentation}

A standard open path eddy covariance package from Campbell Scientific was installed on August 10th, 2009 (Figure 15). A Campbell Scientific CSAT3 sonic anemometer was used to measure instantaneous three-dimensional wind speed $(u, v$, and $w$ ) and sonic temperature $\left(T_{s}\right)$. A LI-COR LI-7500 open-path gas analyzer measured pressure $(P)$, and densities of water vapor $(e)$ and $\mathrm{CO}_{2}(c)$. Supplementary slow response temperature and vapor pressure measurements were taken with a Vaisala HMP-45 mounted directly on the mast at $4 \mathrm{~m}$. All measurements were recorded on a Campbell Scientific CR3000 datalogger mounted at the base of the mast. A Kipp \& Zonen CNR1 net radiometer was added on September 25, 2009. The CNR1 is a four component radiometer that measures incident shortwave and longwave, reflected shortwave, and emitted longwave radiation. Table 2 lists the eddy covariance sensors, specifications, and output variables.

On September 25th, a hose-type traffic counter was placed by the City of Portland one block north of the sensor location on 4th Avenue. The counter measured all three lanes of 4th Avenue. Data was collected as 15-minute vehicle counts, assuming two 
axles for every vehicle. Unfortunately the traffic data was sporadic due to street sweeper activity, capturing 18 days of data out of the 37 days between September 25th and October 31st.

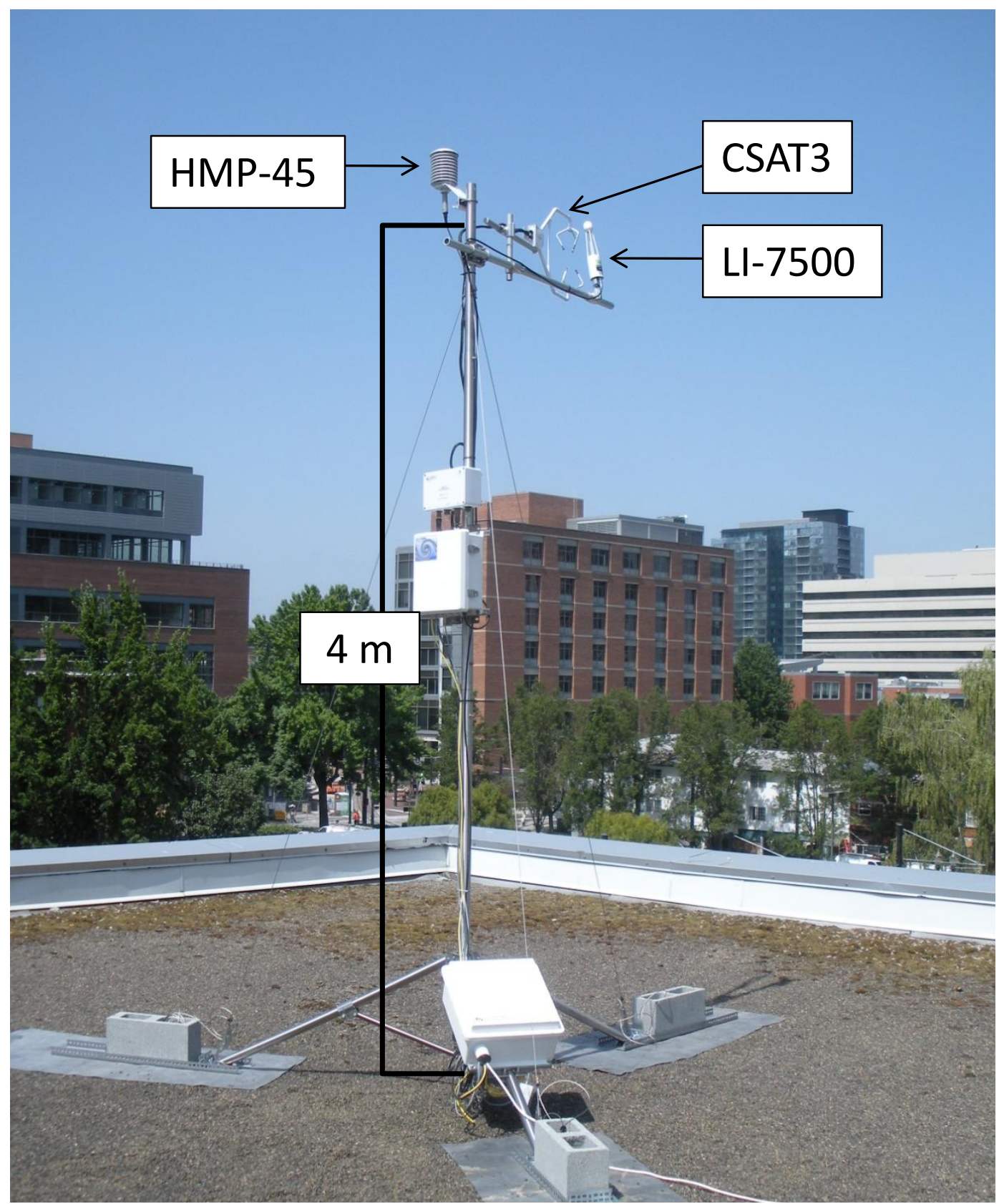

Figure 15: Instruments mounted on the FAB roof. View is facing northwest. 
Table 2: Instrument outputs and resolutions.

\begin{tabular}{|c|c|c|c|c|}
\hline \multirow[t]{2}{*}{ Instrument } & \multicolumn{4}{|c|}{ Measurement Characteristics } \\
\hline & Variable & Units & Rate & Resolution/Accuracy \\
\hline \multicolumn{5}{|l|}{ CSAT3 } \\
\hline & $u$ & $\mathrm{~m} / \mathrm{s}$ & $20 \mathrm{~Hz}$ & $1 \mathrm{~mm} / \mathrm{s}$ (rms) \\
\hline & $V$ & $\mathrm{~m} / \mathrm{s}$ & $20 \mathrm{~Hz}$ & $1 \mathrm{~mm} / \mathrm{s}$ (rms) \\
\hline & $w$ & $\mathrm{~m} / \mathrm{s}$ & $20 \mathrm{~Hz}$ & $0.5 \mathrm{~mm} / \mathrm{s}$ (rms) \\
\hline & $T_{S}$ & ${ }^{\circ} \mathrm{C}$ & $20 \mathrm{~Hz}$ & $0.025^{\circ} \mathrm{C}$ \\
\hline \multicolumn{5}{|l|}{ LI-7500 } \\
\hline & $P$ & $\mathrm{kPa}$ & $20 \mathrm{~Hz}$ & Not Published \\
\hline & $\rho_{V}$ & $\mathrm{~g} / \mathrm{m}^{\wedge} 3$ & $20 \mathrm{~Hz}$ & $0.0047 \mathrm{~g} / \mathrm{m}^{\wedge} 3$ \\
\hline & $\rho_{C}$ & $\mathrm{mg} / \mathrm{m}^{\wedge} 3$ & $20 \mathrm{~Hz}$ & $0.027 \mathrm{mg} / \mathrm{m}^{\wedge} 3$ \\
\hline \multicolumn{5}{|l|}{ HMP-45 } \\
\hline & $T$ & ${ }^{\circ} \mathrm{C}$ & $6 \mathrm{~Hz}$ & $0.2^{\circ} \mathrm{C}$ \\
\hline & $R H$ & $\mathrm{kPa}$ & $4 \mathrm{~Hz}$ & 0.03 \\
\hline \multicolumn{5}{|l|}{ CNR1 } \\
\hline & $Q^{*}$ & $W / m^{\wedge} 2$ & $0.05 \mathrm{~Hz}$ & $\pm 10 \%^{1,2}$ \\
\hline
\end{tabular}

1 The CNR1 net radiometer measures all four solar radiation components: Incident shortwave and longwave, reflected shortwave, and emitted longwave.

The error analysis for the CNR1 is complex, consisting of sensor non-linearity, temperature dependence, tilt response, and sensitivity. This number represents the overall accuracy listed in the product documentation.

\subsection{Processing}

Data was processed using EdiRe, a program developed by John Moncrieff and Robert Clement at the University of Edinburgh (Moncrieff, 2006). Processing was performed according to the procedure in Section 2.3, with the following parameters and exceptions: 
1. Despike: EdiRe adds an additional criterion, "Spike \% Consistency", for a data point to be labeled as a spike. This is the maximum allowable percentage reduction in spike magnitude on its downward travelling leg. For example, a value of $50 \%$ for this parameter would imply that a spike producing a positive value of 10 would only have to recover to a value of 5 in order for the routine to identify it as a spike (Clement, 2001). This parameter is left at the default value of $30 \%$.

2. Coordinate Rotation: The two-rotation method from Eqs. (16) and (17) is used. The third rotation angle $\gamma$ is calculated, but not applied.

3. Block Averaging: A standard 30-minute averaging period was used, as recommended by Aubinet et al. (2000) and Foken (2008a). The measurement height $Z_{m}$ for this study was less than $15 \mathrm{~m}$ for all wind directions, putting it well below measurement heights where longer time averages are generally considered necessary (Berger et al., 2001); (Finnigan et al., 2003). Because of this fact, ogive plots were not generated.

4. Flux Calculations: Sensible heat flux (Eq. (9)) is calculated using the sonic temperature, $T_{S}$. This necessitates the sonic temperature correction to sensible flux as discussed in Section 2.3.

5. Frequency Response Corrections: Due to the failure to meet the assumptions associated with established frequency response correction methods, these corrections were not applied in this study. This leads to an underestimation of all fluxes by $3-5 \%$, based on correction factors from Aubinet et al. (2000). 
6. WPL Corrections: The latent heat and $\mathrm{CO}_{2}$ fluxes are corrected according to Eqs. (12) and (13), respectively.

7. Sonic Temperature Correction: Equation (22) is used to correct the sensible heat flux. The value for $\bar{T}$ is taken from the HMP-45 temperature measurement.

8. Convergence Test: Because frequency response corrections are not performed in this study, only a single pass was made by the correction algorithms.

9. Stationarity Test: Stationarity was calculated for $\overline{w^{\prime} T^{\prime}}, \overline{w^{\prime} \rho_{v^{\prime}}}$, and $\overline{w^{\prime} \rho_{c}{ }^{\prime}}$. Values were recorded, but not used as filters.

Half-hour block averages from EdiRe were stored as comma separated variables and analyzed in a spreadsheet. Each half-hour block average was filtered for spike count, compass wind direction, tilt angle $\beta$, and precipitation according to Table 3. Blocks with spike counts greater than $2 \%$ of the total number of measurements $(36,000$ total for a 30 minute block at $20 \mathrm{~Hz}$ ) were rejected. This value was chosen as a compromise between values of $1 \%$ recommended by Vickers \& Mahrt (1997) and 10\% recommended by Mauder \& Foken (2004). Blocks with $|\beta|$ greater than $10^{\circ}$ are rejected due to distortion of turbulent stresses, as recommended in McMillen (1988). Blocks with mean wind directions between $10^{\circ}$ and $190^{\circ}$ were rejected as described in Section 3.1. The open path gas analyzer does not make accurate measurements in the rain, so blocks where precipitation was measured were rejected. 
Table 3: Filter criteria for half-hour blocks. The spike count filter was applied to all measured variables. Precipitation was cross-referenced to a weather station located 4 blocks to the east of the tower.

\begin{tabular}{|l|c|c|c|c|}
\hline Variable & Spike Count & Roll Angle $\boldsymbol{\beta}$ & Wind Direction & Precipitation \\
\hline Acceptance Criteria & $<720(2 \%)$ & $|\beta|<10$ & $<10^{\circ}$ or $>190^{\circ}$ & 0 \\
\hline
\end{tabular}




\section{Results and Discussion}

Measurements of from the months of August, September, and October are presented. Measurements of heat and $\mathrm{CO}_{2}$ fluxes and $\mathrm{CO}_{2}$ concentrations are evaluated against measurements taken in other cities by established researchers. Sensible heat and $\mathrm{CO}_{2}$ fluxes are also compared to inventory estimates for traffic emissions. Fluxes and $\mathrm{CO}_{2}$ concentration follow expected daily cycles, and amplitudes of each are within a reasonable range of other studies. The inventory comparison indicates that the measurements underestimate vehicular emissions of sensible heat and $\mathrm{CO}_{2}$.

\subsection{Wind}

As anticipated, August was the most favorable month for wind direction, while the shift to prevailing winter winds became apparent in October (Figure 16). This can also be seen in Table 5, where over half of the 30-minute block averages were filtered out due to wind direction in October, compared to $17 \%$ for August and $30 \%$ for September. Half-hour average wind speeds measured at the tower for all three months were typically in the $1.0-1.3 \mathrm{~m} / \mathrm{s}$ range, with a maximum of $3.1 \mathrm{~m} / \mathrm{s}$.

Table 4: Monthly wind speed

\begin{tabular}{lccc}
\hline Month & \multicolumn{3}{c}{ Wind Speed $(\mathrm{m} / \mathrm{s})$} \\
\hline & Max & Average & Standard Dev. \\
\cline { 2 - 4 } August & 3.1 & 1.2 & 0.78 \\
September & 2.8 & 1.3 & 0.73 \\
October & 2.3 & 1.0 & 0.58 \\
\hline
\end{tabular}




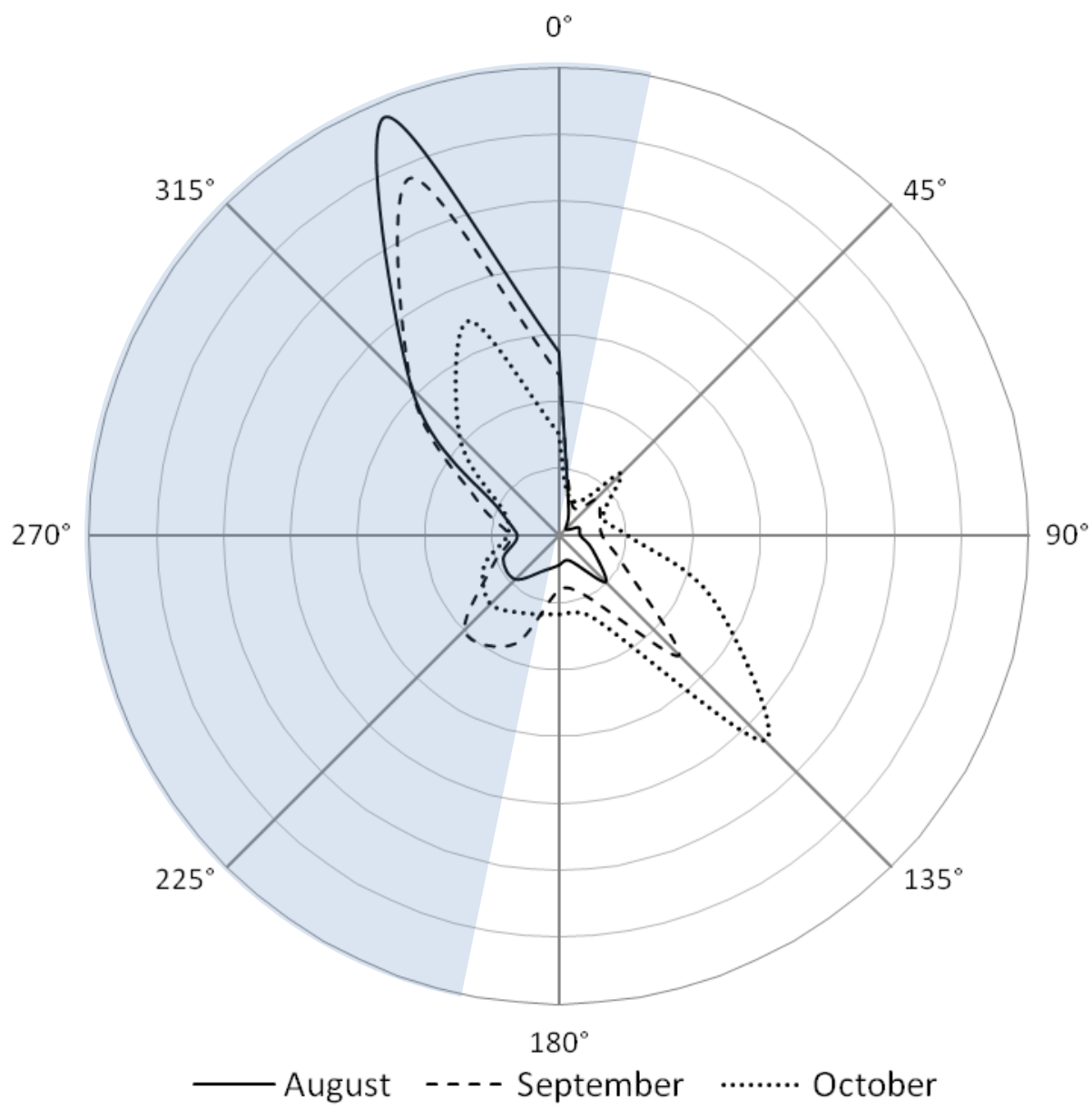

Figure 16: Wind frequency for August, September, and October 2009. The shaded region represents accepted wind vectors.

\subsection{Data Rejection}

Table 5 shows the number of 30 minute blocks collected and rejected. Wind direction was by far the most common reason for rejecting data blocks, removing $51 \%$ of October data and $34 \%$ of all data. Precipitation, the next most common rejection criteria, removed less than $6 \%$ of all data. Just over $3 \%$ of the blocks were rejected due to roll angle $\beta$, but it should be noted that on further inspection over $80 \%$ of these 
blocks were also rejected for wind direction. Very few blocks were rejected for excessive spikes, and when inspected all of these rejections could be attributed to precipitation. Data rejected in October was disproportionately skewed to daytime hours, when wind from the southeast was most prevalent. Combined with the fact that over half of October values were rejected, data from this month cannot necessarily be considered representative.

Table 5: Rejection of half-hour blocks by category. Some blocks were rejected by multiple criteria.

\begin{tabular}{|c|c|c|c|c|c|c|}
\hline Month & Collected & & & Rejectec & & \\
\hline & & $\begin{array}{l}\text { Spike } \\
\text { Count }\end{array}$ & $\begin{array}{c}\text { Wind } \\
\text { Direction }\end{array}$ & $\begin{array}{c}\text { Roll Angle } \\
\beta \\
\end{array}$ & Precipitation & Total (\%) \\
\hline August & 1003 & 1 & 174 & 22 & 34 & $197(20)$ \\
\hline September & 1299 & 3 & 393 & 47 & 78 & 444 (34) \\
\hline October & 1280 & 4 & 651 & 46 & 94 & $702(55)$ \\
\hline Total & 3582 & 8 & 1218 & 115 & 206 & $1343(37)$ \\
\hline
\end{tabular}

\section{3 $\mathrm{CO}_{2}$ Concentration and Flux}

Figure 17 shows average concentrations of $\mathrm{CO}_{2}$ for the three observed months. Averages are the ensemble mean for each time of day. Error bars represent \pm 1 standard deviation from the ensemble mean, and are intended to give a general sense of day-today variations. A clear diurnal cycle is evident, with concentrations typically reaching a daily maximum at 8:00 AM and a daily minimum at 4:00 PM. The morning peak is generally attributed to a combination of morning traffic emissions and a shallow mixed boundary layer, with a minor contribution (in urban areas) from nighttime soil 
Table 6: $\mathrm{CO}_{2}$ concentration and flux statistics

\begin{tabular}{|c|c|c|c|c|c|c|}
\hline \multirow[t]{2}{*}{ Month } & \multicolumn{3}{|c|}{$\begin{array}{c}\text { Average Daily } \mathrm{CO}_{2} \text { Concentration } \\
(\mu \mathrm{mol} / \mathrm{mol})\end{array}$} & \multicolumn{3}{|c|}{$\begin{array}{l}\text { Average Daily } \mathrm{CO}_{2} \text { Flux } \\
\left(\mu \mathrm{mol} / \mathrm{m}^{2} \mathrm{~s}\right)\end{array}$} \\
\hline & Min & Average & Max & Min & Average & Max \\
\hline August & 369 & 379 & 393 & 0.8 & 6.1 & 14.1 \\
\hline September & 373 & 388 & 407 & 0.5 & 6.6 & 13.7 \\
\hline October & 382 & 399 & 414 & -0.4 & 7.1 & 15.2 \\
\hline Average & 374 & 388 & 404 & 0.4 & 6.6 & 14.2 \\
\hline
\end{tabular}

respiration. The afternoon minimum is caused primarily by the expansion of the atmospheric boundary layer and convective mixing, with some contribution from uptake of $\mathrm{CO}_{2}$ by vegetation. Minimum values averaged $374 \mathrm{ppm}$ (Table 6), with individual measurements as low as 304 ppm. Maximum values averaged 404 ppm (Table 6), with individual measurements as high as $495 \mathrm{ppm}$. The diurnal profiles are similar to measurements taken in other cities such as Vancouver, B.C. (Reid \& Steyn, 1997), Chicago (Grimmond et al., 2002), Mexico City (Velasco et al., 2005), and Basel, Switzerland (Vogt et al., 2006). Amplitudes in each city varied, with all but Edinburgh and Portland exceeding the Mauna Loa background concentration for their year by 6 $10 \mathrm{ppm}$. Urban areas are generally expected to have higher than background $\mathrm{CO}_{2}$ concentrations, but these measurements averaged the same as the current Mauna Loa background of 388ppm (Tans, 2009). The individual maximum concentration measurement was only matched in Basel, the only study where measurements were similarly close to street level. The individual minimum measurement is $50 \mathrm{ppm}$ lower than in any of the other cities. Also of interest are the increase in concentrations each month and the development of a second peak in the evenings of October. One likely 

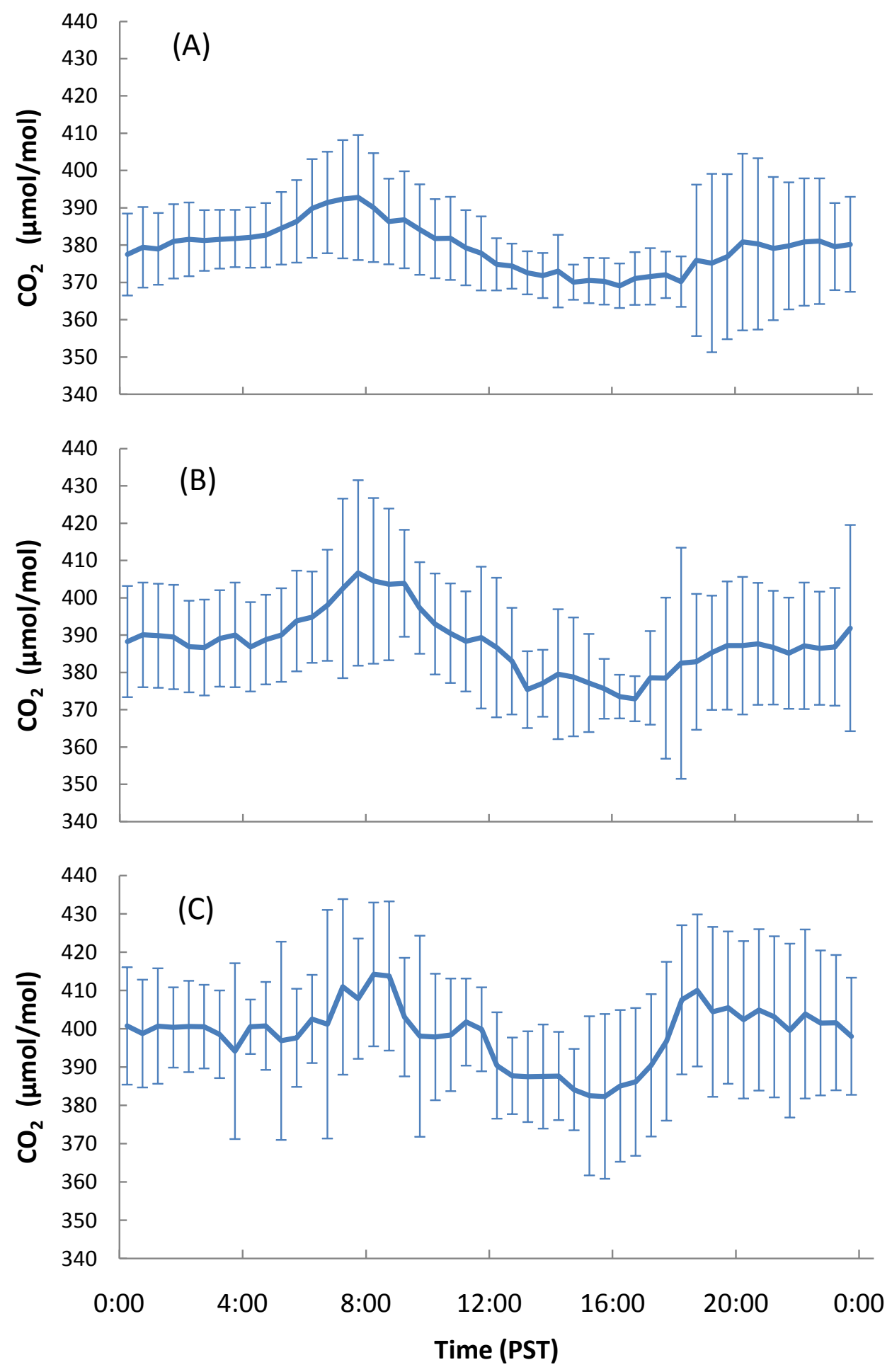

Figure 17: Average diurnal pattern of $\mathrm{CO}_{2}$ concentration for August (A), September (B), and October (C) 2009. Vertical bars represent \pm 1 standard deviation. 

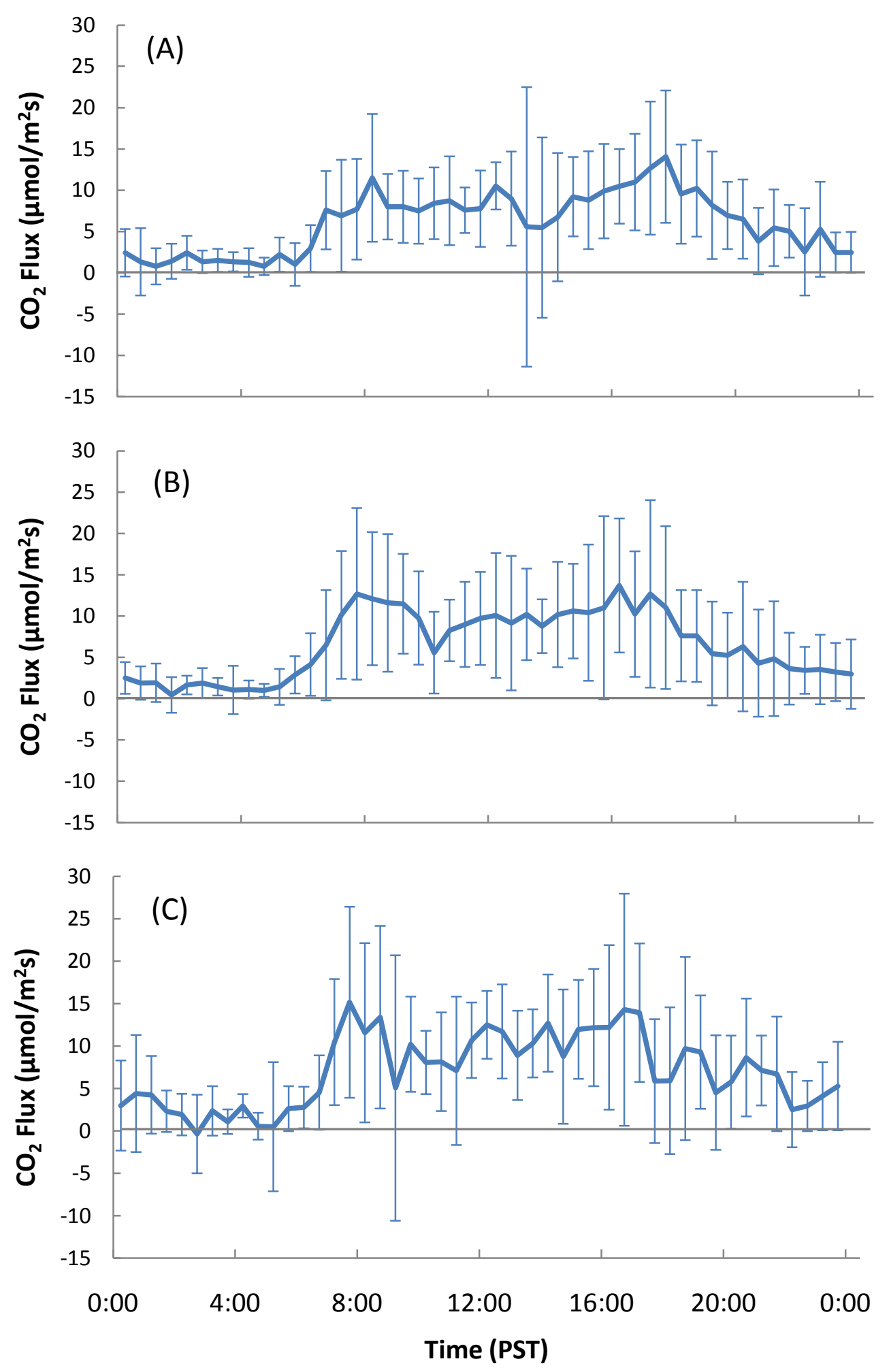

Figure 18: Average diurnal pattern of $\mathrm{CO}_{2}$ flux for August (A), September (B), and October (C) 2009. Vertical bars represent \pm 1 standard deviation. 
cause for this increase is that traffic volume typically increases both when summer vacation ends for $\mathrm{K}-12$ students at the end of August and when classes start at nearby Portland State University at the end of September. Traffic data from August and early September was not available to investigate this possibility.

Figure 18 shows average diurnal $\mathrm{CO}_{2}$ flux profiles for the three observed months. The two primary sources of $\mathrm{CO}_{2}$ in an urban environment are vehicle emissions and building heating emissions (Pataki et al., 2003). Vehicle emissions tend to dominate the summer months when little building heating is needed. Vehicle emissions also dominate at lower heights, because the majority of building exhaust is released at roof level. The diurnal $\mathrm{CO}_{2}$ flux pattern should therefore be attributable almost entirely to daily traffic loads. In this case a strong correlation between traffic volume and $\mathrm{CO}_{2}$ flux would be expected. A direct comparison of half-hourly blocks where both $\mathrm{CO}_{2}$ flux and traffic data were present yielded a surprisingly poor correlation. However, average weekday profiles of $\mathrm{CO}_{2}$ flux and traffic volume in October were strongly correlated, with a coefficient of 0.91. In Figure 19 the traffic peaks at 8:00 AM and 5:00 PM can be seen to match the corresponding peaks in $\mathrm{CO}_{2}$ flux. The most likely cause for the lack of a direct correlation is simply a sparse data set (approximately $25 \%$ of the half-hour blocks could be used) that was disproportionately skewed to nighttime blocks with lower traffic and more variable flux measurements. While individual measurements show a negative flux, on average the flux is almost always positive, indicating that the downtown Portland landscape is always a net source of $\mathrm{CO}_{2}$. 
Some caution must be taken when comparing $\mathrm{CO}_{2}$ fluxes in different cities, as sources are highly variable, even in cities with similar geography, climate, and population densities. Because these measurements are preliminary and in violation of some standard eddy covariance practices, it is worthwhile to evaluate them against published data. $\mathrm{CO}_{2}$ flux profiles are consistent with other urban studies in Chicago (Grimmond et al., 2002), Edinburgh (Nemitz et al., 2002), Marseille (Grimmond et al., 2004), Mexico City (Velasco et al., 2005), and Basel (Vogt et al., 2006). Measurements in all of these cities showed greater average $\mathrm{CO}_{2}$ fluxes, most significantly in Edinburgh (22 $\left.\mu \mathrm{mol} / \mathrm{m}^{2} \mathrm{~s}\right)$ and Marseille $\left(20 \mu \mathrm{mol} / \mathrm{m}^{2} \mathrm{~s}\right)$. That all of the other urban measurements were higher can be attributed at least in part to the low measurement height, which effectively neglects most contributions from building heating by burning natural gas (or other direct heating fuels). A coarse inventory based on EIA data for Oregon shows natural gas consumption emits 1 gram of $\mathrm{CO}_{2}$ for every 1.7 grams emitted by gasoline for the combined months of August, September, and October (EIA, 2008b). Assuming at least $50 \%$ and at most $100 \%$ of the of the EIA building emissions are neglected indicates true urban $\mathrm{CO}_{2}$ fluxes of between 8.5 and $10.5 \mu \mathrm{mol} / \mathrm{m}^{2} \mathrm{~s}$. These values are more in line with the measurements in Chicago $\left(10 \mu \mathrm{mol} / \mathrm{m}^{2} \mathrm{~s}\right)$, Mexico City $\left(9 \mu \mathrm{mol} / \mathrm{m}^{2} \mathrm{~s}\right)$, and Basel $\left(12.5 \mu \mathrm{mol} / \mathrm{m}^{2} \mathrm{~s}\right)$.

Filtering for stationarity showed a measurable increase in average $\mathrm{CO}_{2}$ fluxes. Applying the stationarity criteria as described in Eq. (23) removed $44 \%$ of the blocks for August, September, and October combined. The resulting average flux was $25 \%$ greater 


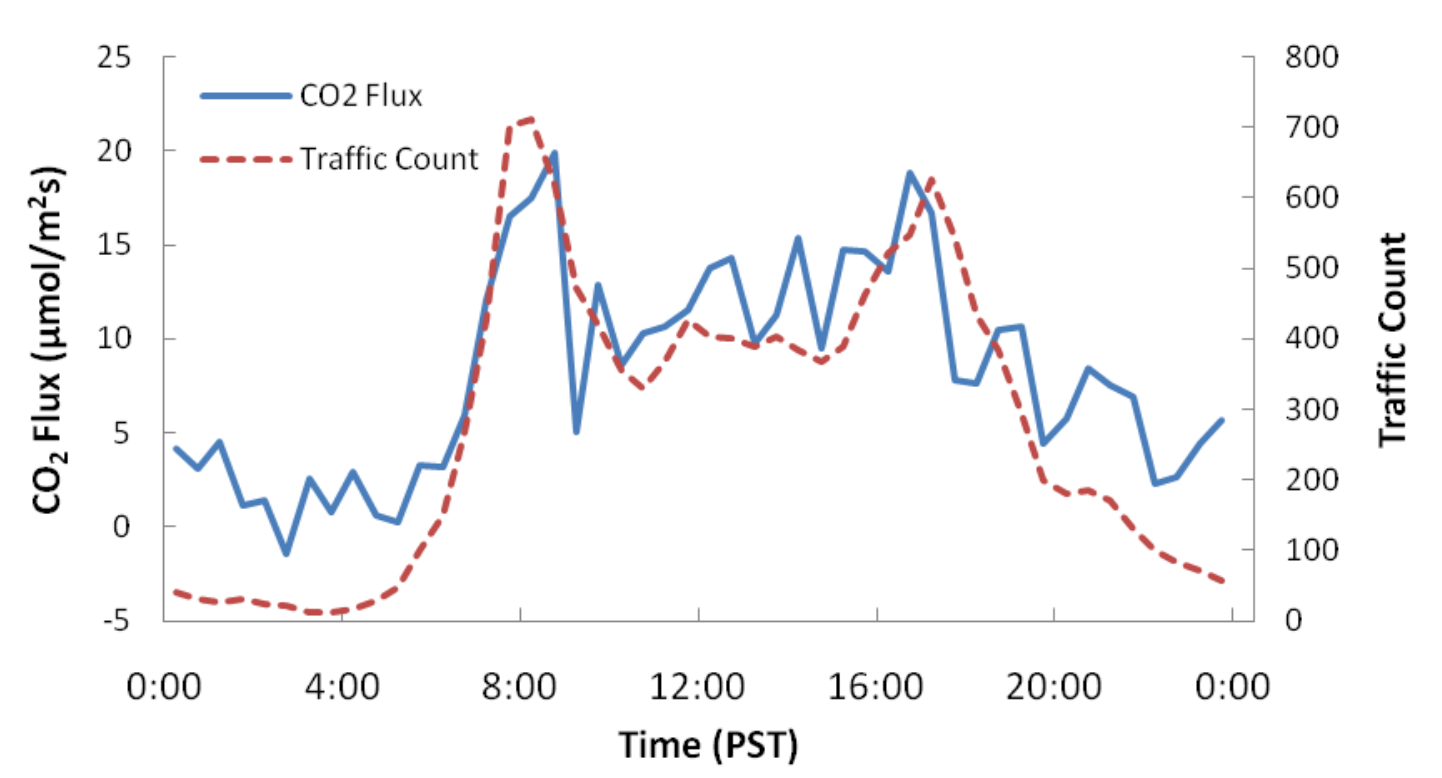

Figure 19: Average $\mathrm{CO} 2$ flux and traffic count for weekdays in October. The correlation coefficient for the two data sets is 0.91 .

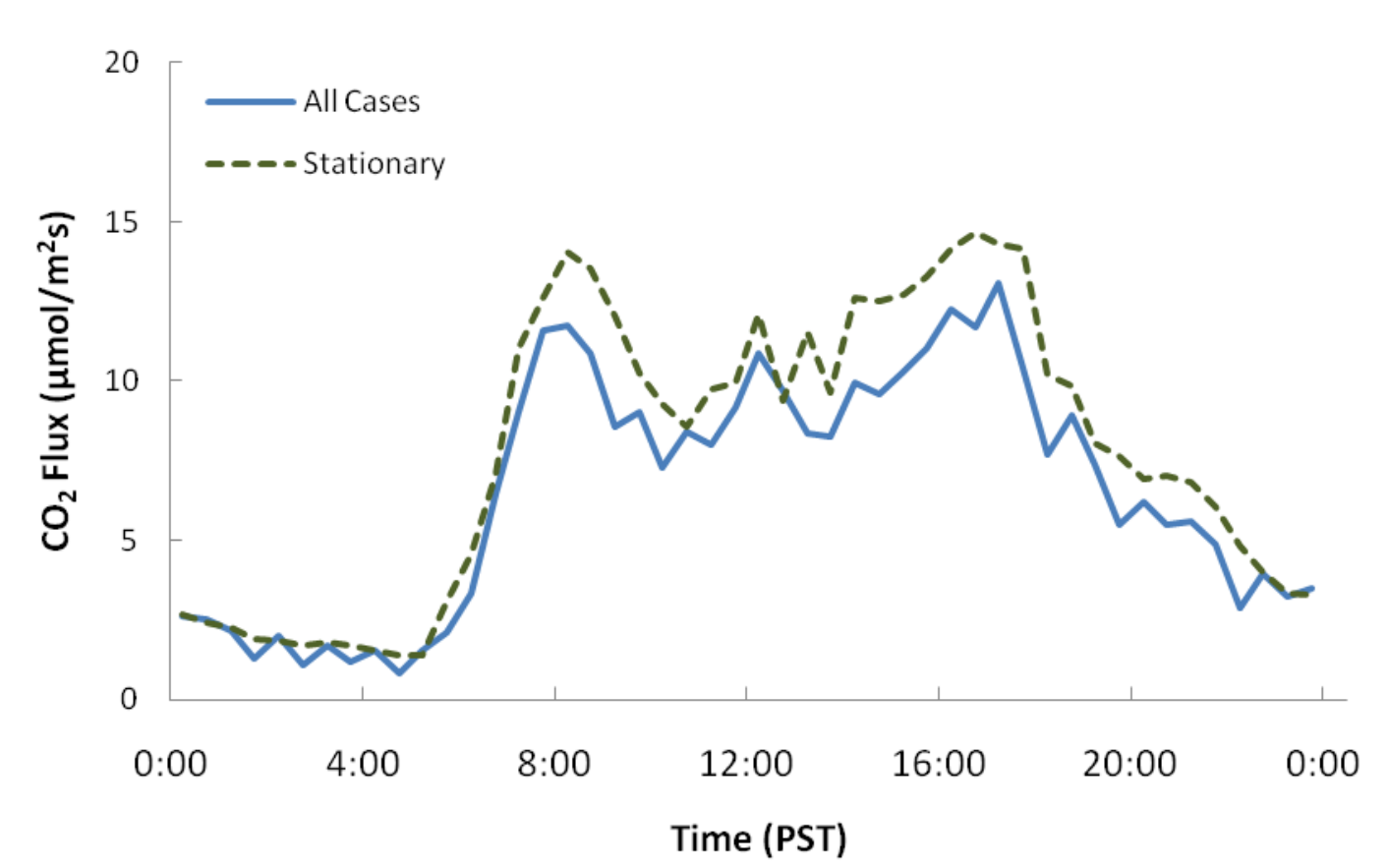

Figure 20: Combined diurnal $\mathrm{CO}_{2}$ flux profile for August, September, and October. Blocks were considered stationary for $R N_{\text {cov }}<30 \%$. 
(8.1 $\mu \mathrm{mol} / \mathrm{m}^{2} \mathrm{~s}$ ) than for all cases (Figure 20). This is the expected result, as nonstationarity indicates turbulence is not fully developed, which reduces scalar transport (Pope, 2000).

\subsection{Heat Fluxes}

Half-hour average diurnal fluxes of sensible and latent heat are shown for August, September, and October in Figures 21, 22, and 23, respectively. Sensible fluxes are slightly negative at night, then rise through the morning until reaching a peak in the afternoon at 2:00 PM and returning to zero at approximately 7:30 PM. Of the two source terms in Eq. (1), solar radiation is generally the dominant contributor to sensible heat, particularly in summer months (Grimmond et al., 2004); (Offerle et al., 2006). The strong influence of solar radiation on sensible heat flux was observed for October (Figure 24), but the phase of sensible heat flux lags slightly due to storage effects. Latent heat flux is almost always positive throughout the diurnal cycle. Sources of latent heat are vegetative evapotranspiration, anthropogenic combustion processes, and evaporated precipitation. Latent heat flux rose during the morning as solar activity activated photosynthesis and surface evaporation, leveled off during the late morning and afternoon, then fell back to nighttime levels at sunset. Due to the highly variable nature of precipitation, $Q_{E}$ shows significantly more variation relative to magnitude than sensible flux. This is apparent in the profiles for the rainier months of September (Figure 22) and October (Figure 23). Sensible flux dominates the turbulent fluxes in 


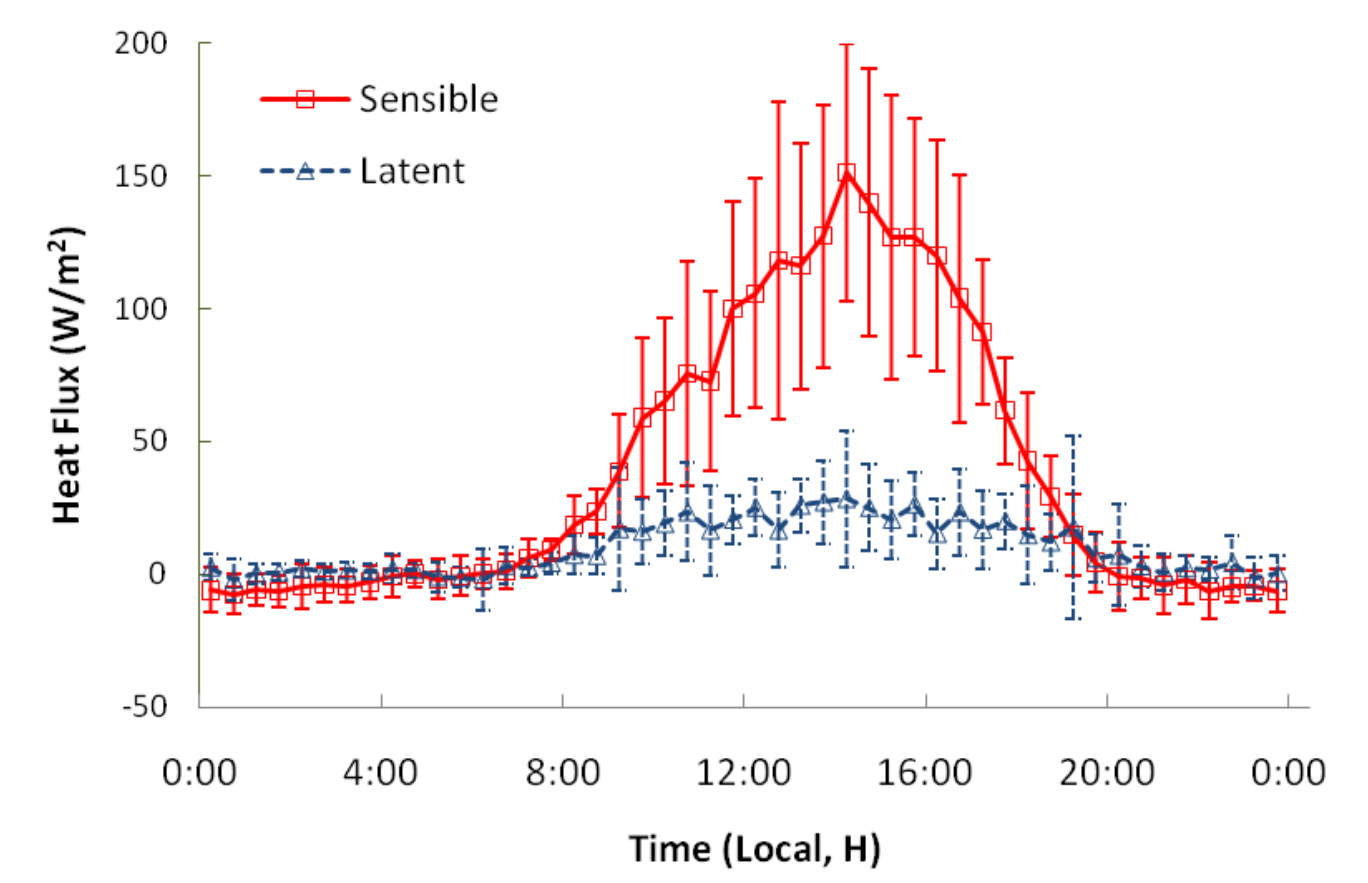

Figure 21: Sensible and latent heat flux profiles for August. Vertical bars represent \pm 1 standard deviation.

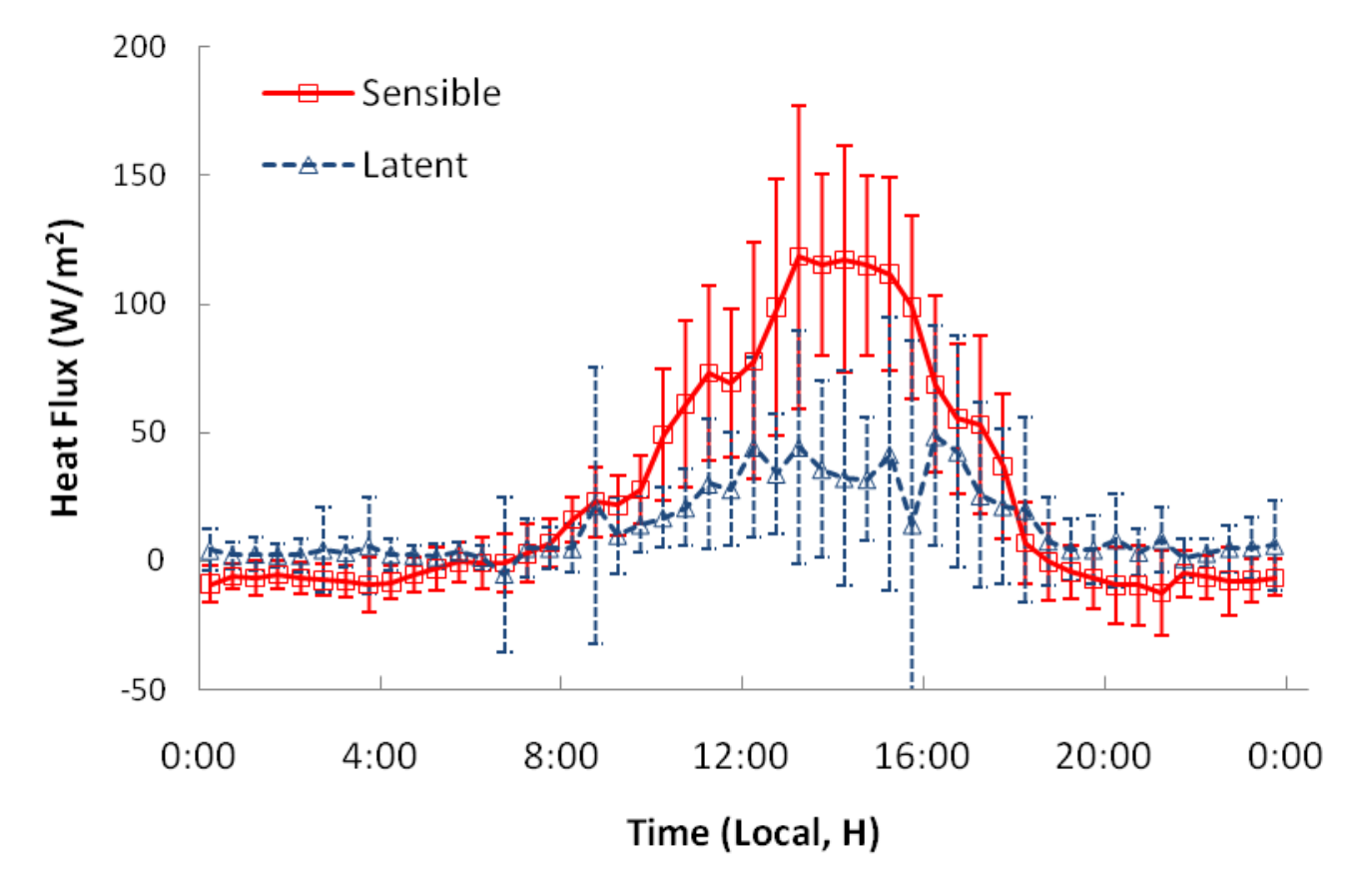

Figure 22: Sensible and latent heat flux profiles for September. Vertical bars represent \pm 1 standard deviation. 


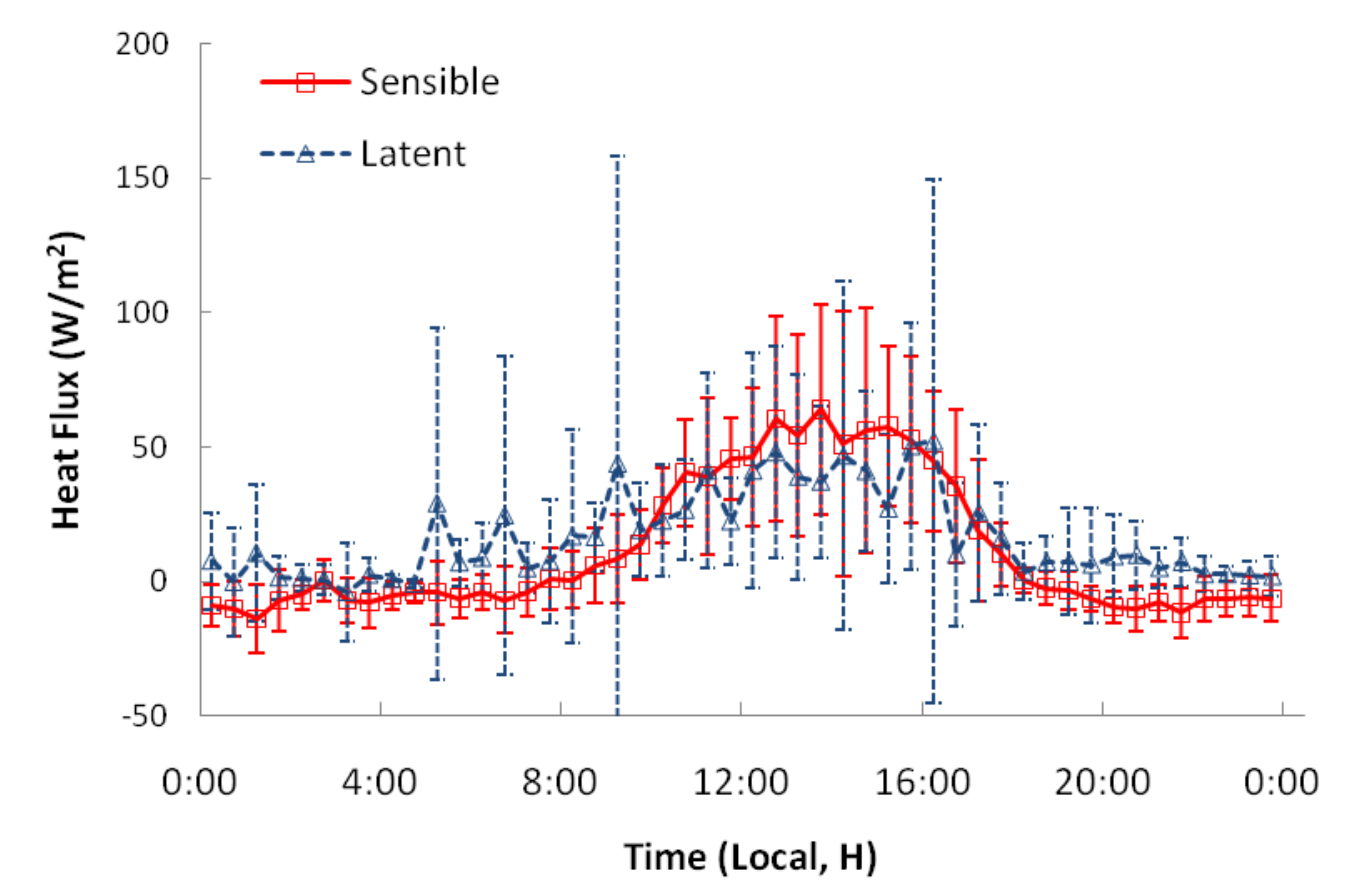

Figure 23: Sensible and latent heat flux profiles for October. Vertical bars represent \pm 1 standard deviation.

August, with a daily average four times that of the latent flux (Figure 21). The changes in weather as the season transitions from summer to fall can be seen to affect both the sensible and latent fluxes. Sensible heat flux drops significantly while latent flux increases, until average daily latent flux exceeds sensible flux in October (Figure 23). Averages and peaks of heat fluxes are listed in Table 7. Even greater care must be taken when comparing heat fluxes in different cities than when comparing $\mathrm{CO}_{2}$ fluxes. In addition to concerns about variations in population density and source distributions, all aspects of ground cover and local climate can affect the turbulent heat fluxes. That said, the general diurnal pattern and magnitude relative to solar radiation of turbulent heat fluxes measured in Portland was consistent with results from Baltimore (Grimmond et 
al., 2002), Edinburgh (Nemitz et al., 2002), Marseille (Grimmond et al., 2004), and Łódź (Offerle et al., 2005), cities which are at similar latitudes.

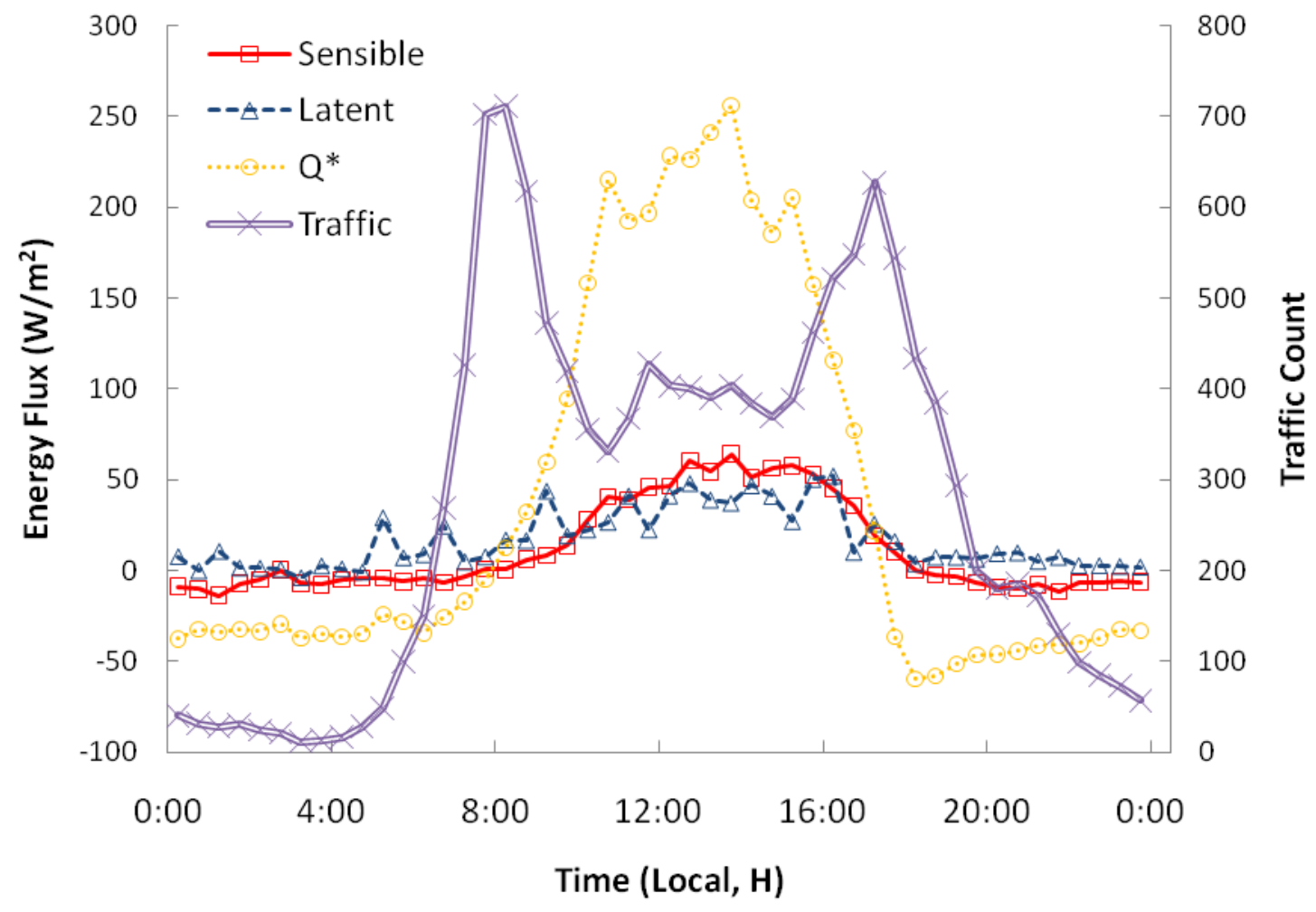

Figure 24: Average daily profile of energy flux and traffic for October.

Table 7: Monthly sensible and latent heat flux statistics.

\begin{tabular}{lcccccc}
\hline Month & \multicolumn{3}{c}{$\begin{array}{c}\text { Average Daily Sensible Heat Flux } \\
\left(\mathbf{W} / \mathbf{m}^{\mathbf{2}}\right)\end{array}$} & & \multicolumn{2}{c}{$\begin{array}{c}\text { Average Daily Latent Heat Flux } \\
\left(\mathbf{W} / \mathbf{m}^{\mathbf{2}}\right)\end{array}$} \\
\hline & Min & Average & Max & Min & Average & Max \\
\cline { 2 - 7 } August & -7.5 & 39.1 & 151.3 & -2.0 & 10.1 & 28.3 \\
September & -12.5 & 26.5 & 118.4 & -5.1 & 14.3 & 48.6 \\
October & -13.8 & 11.8 & 64.0 & -4.1 & 16.9 & 52.2 \\
\hline Average & -8.6 & 26.4 & 106.7 & 0.2 & 13.5 & 39.2 \\
\hline \hline
\end{tabular}




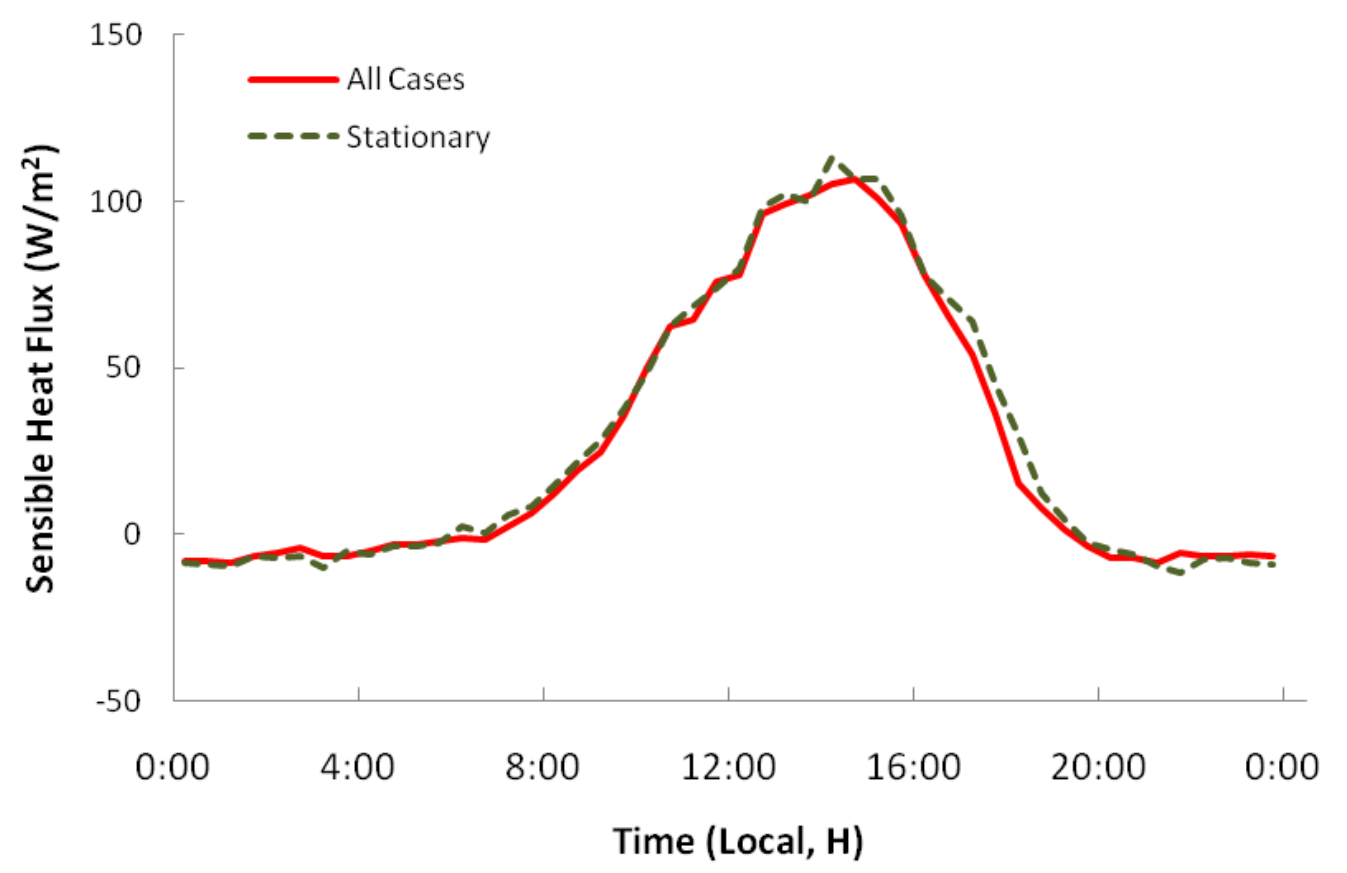

Figure 25: Combined diurnal sensible heat flux profile for August, September, and October. Blocks were considered stationary for $R N_{\text {cov }}<30 \%$.

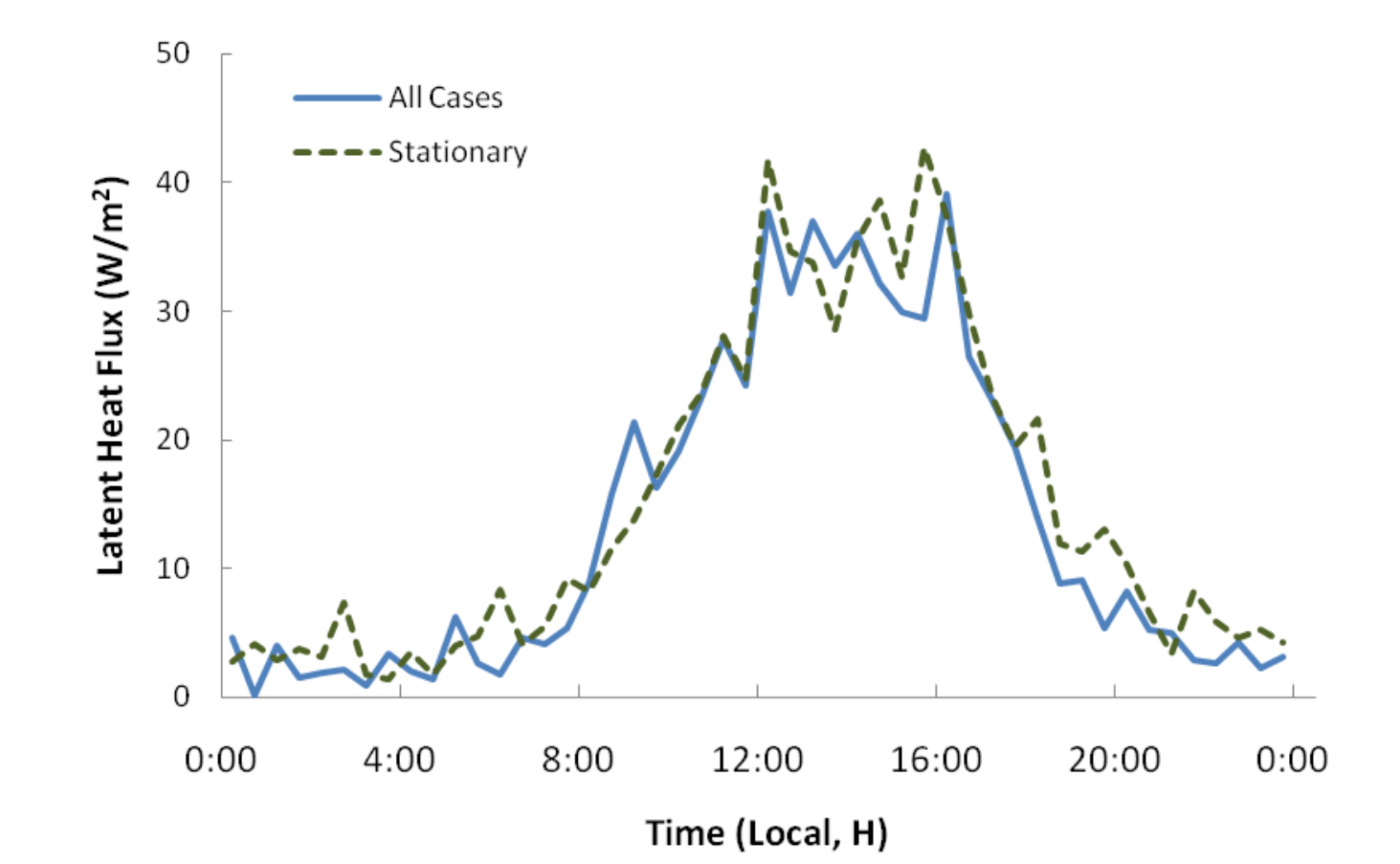

Figure 26: Combined diurnal latent heat flux profile for August, September, and October. Blocks were considered stationary for $R N_{\text {cov }}<30 \%$. 
Applying the stationarity criteria to sensible and latent heat fluxes led to rejection of $37 \%$ and $62 \%$ of the block averages, respectively. Stationarity had little influence on the average profiles of either heat flux (Figures 25 and 26). Separation of fluxes by wind vector was neglected due to lack of data in wind sectors 2 and 3 of Figure 14.

\subsection{Sensible Heat and $\mathrm{CO}_{2}$ Flux from Vehicles}

Anthropogenic heat flux is often estimated as the residual of the surface energy balance, as in Eq. (3). In order to assess the validity of this approach, an inventory of sensible heat and $\mathrm{CO}_{2}$ emissions from vehicles were compared to measured values for late September and October, when traffic count data was available. A multiple leastsquares linear regression was performed of the form:

$$
y=A_{0}+A_{1} x_{1}+A_{2} x_{2}+\cdots+A_{n} x_{n}
$$

where $y$ is the dependent variable, $x_{n}$ are the independent variables, and $A_{n}$ are the regression coefficients. To determine if the vehicular contribution to heat flux could be detected, sensible heat flux was taken to be the dependent variable, while traffic count and incident solar radiation were taken as independent variables. Incident solar radiation was substituted for net solar radiation because the footprint for outbound radiation included only the FAB roof and was not considered representative of the area measured by the flux instruments. Only filtered half-hour blocks with concurrent traffic counts were used, limiting the regression to 419 data points. Regression results are listed in Table 8. The "Slope" column indicates the coefficients for each independent 
variable in the regression. The t-Value is the Student t-statistic calculated based on a null hypothesis that each coefficient $A_{n}=0$, versus an alternative hypothesis that $A_{n} \neq 0$. The confidence interval is based on a double-sided t-distribution. The $99.6 \%$ confidence interval indicates a statistically significant correlation between traffic count and sensible heat flux.

Table 8: Regression results for incident solar radiation and traffic count versus sensible heat flux. The regression was based on 419 measurements and yielded an adjusted $R^{2}$ value of 0.71 .

\begin{tabular}{lccc}
\hline & Slope & t-Value & Confidence Interval \\
\cline { 2 - 4 }$K \downarrow$ & 0.169 & 28.462 & $100.0 \%$ \\
Traffic Count & 0.014 & 2.868 & $99.6 \%$ \\
\hline \hline
\end{tabular}

Comparing the slope of traffic count versus sensible heat flux to expected values of heat released from vehicles requires an inventory based estimate of vehicular heat emissions. Because the source area is unknown, a scaled approach based on that of Sailor \& Lu (2004) is used. First, a representative unit of urban terrain (a city block) is chosen (Figure 27). The vehicular heat release $Q_{V}$ in this area is given by:

$$
Q_{V}=N_{V} \frac{N_{L}}{N_{M}} \frac{L \cdot E V}{A \cdot T}
$$

where $N_{V}$ is the number of vehicles counted, $N_{L}$ is the total number of traffic lanes in the unit, $N_{M}$ is the number of traffic lanes measured by the counter, $L$ is the length that each vehicle travels (in meters), $E V$ is the energy release of each vehicle per meter of travel, $A$ is the area of the unit, and $T$ is the period of the vehicle count (in seconds). The relative traffic volume on the unmeasured lanes and the average fuel economy of 


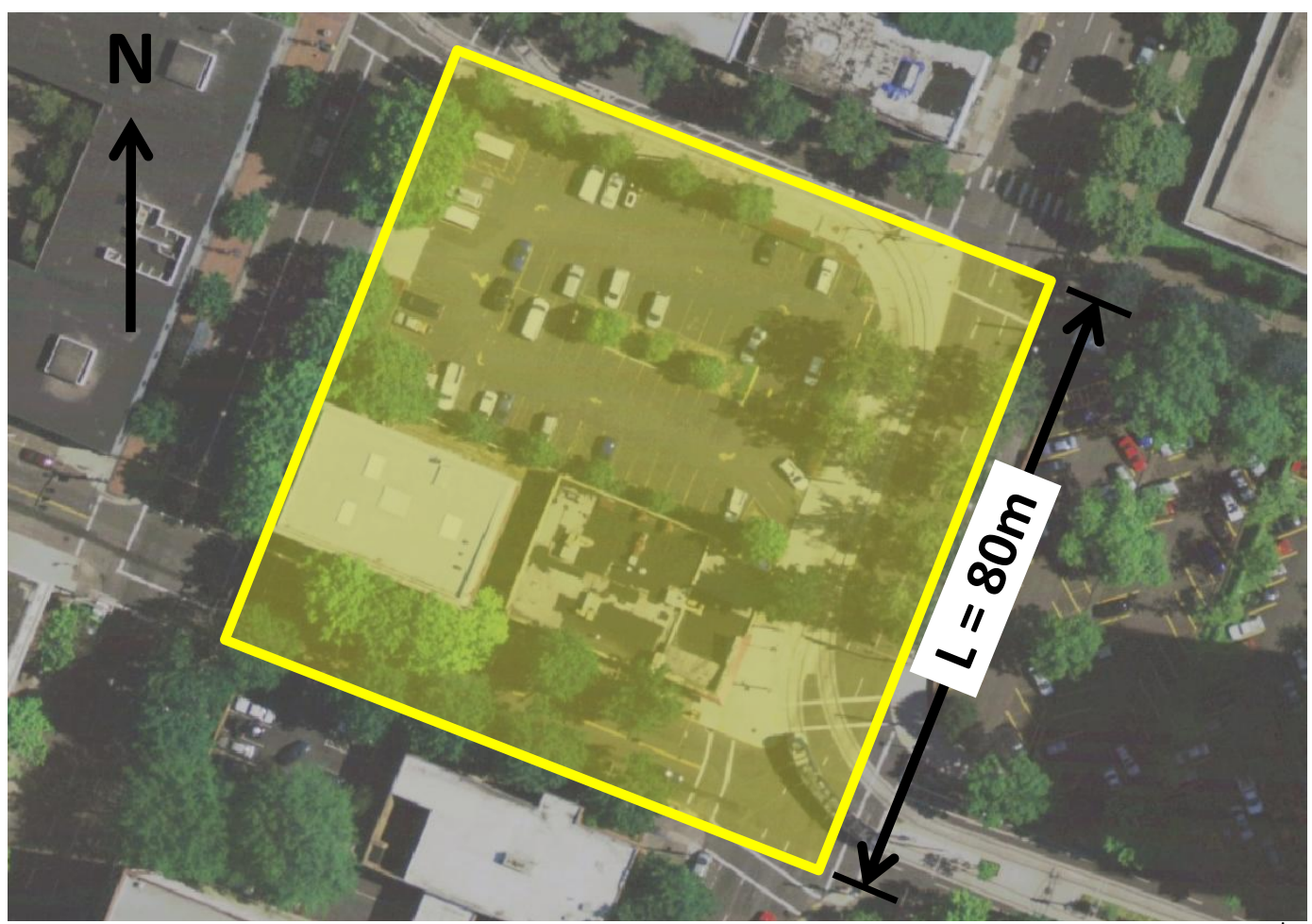

Figure 27: Representative unit chosen for estimating heat from vehicles. $4^{\text {th }}$ Avenue is the three lane, one-way street running southwest to northeast on the right side of the figure. Harrison Street is the two lane, two way street running along the bottom. The traffic counter is placed on $4^{\text {th }}$ Avenue one block northeast of the highlighted area. The unit is taken to be square, so $A=L^{2}=6400 \mathrm{~m}^{2}$. Image courtesy of City of Portland.

the fleet are unknown, so reasonable upper and lower bounds must be chosen. The measured street (4th Avenue) is a three lane road, so $N_{M}=3$. The two unmeasured lanes are on a cross street (Harrison Street) with less traffic than busy 4th Avenue. A lower bound for $N_{L} / N_{M}$ is set as 1 , which assumes that traffic on the unmeasured street is negligible. An upper bound for $N_{L} / N_{M}$ of $5 / 3$ is chosen, which assumes that traffic volume per lane is equal on each street. Energy release estimates are based on the 2009 average fuel efficiency for passenger cars of 24 mpg (EPA, 2009), which yields an $E V$ of $3310 \mathrm{~J} / \mathrm{m}$. Upper and lower bounds for $E V$ are chosen based on $20 \mathrm{mpg}$ (3975 
$\mathrm{J} / \mathrm{m})$ and $28 \mathrm{mpg}(2840 \mathrm{~J} / \mathrm{m})$, in order to cover uncertainties in fleet composition. Figure 27 gives $L$ and $A$ as $80 \mathrm{~m}$ and $6400 \mathrm{~m}^{2}$, respectively. The period for vehicle counts was 30 minutes, or $1800 \mathrm{~s}$. Rearranging Eq. (25) and applying these values yields a slope of $0.020<Q_{V} / N_{V}<0.046\left(\mathrm{~W} /\right.$ vehicle $\left.\cdot \mathrm{m}^{2}\right)$, with a middle estimate of 0.031 . This places the measured slope well underneath the lowest estimate, at $45 \%$ of the middle value. While this could indicate that heat flux is underestimated by the eddy covariance measurements, it may also represent two neglected sensible heat sinks: storage, $\Delta Q_{S}$, and precipitation runoff. Due to the complex interactions of multiple heat sources and sinks in an urban environment, this result is inconclusive without measurements of these two quantities.

Carbon dioxide sources, on the other hand, are much simpler in an urban environment, where vehicle emissions are by far the largest source at street level. A similar comparison of the expected vehicular $\mathrm{CO}_{2}$ emissions to the measured $\mathrm{CO}_{2}$ flux can help reveal whether the fluxes are underestimated by the eddy covariance measurements. In this case the equation for vehicular emissions, $C_{V}$, is:

$$
C_{V}=N_{V} \frac{N_{L}}{N_{M}} \frac{L \cdot E C}{A \cdot T}
$$

where $E C$ is the average $\mathrm{CO}_{2}$ emission in moles per meter traveled. Based on the same fuel efficiencies used above, the lower, middle, and upper estimates of $E C$ are 4400 $\mu \mathrm{mol} / \mathrm{m}, 5200 \mu \mathrm{mol} / \mathrm{m}$, and $6200 \mu \mathrm{mol} / \mathrm{m}$, respectively. Applying these values to Eq. (23) yields a slope of $0.031<C_{V} / N_{V}<0.072\left(\mu \mathrm{mol} /\right.$ vehicle $\left.\cdot \mathrm{m}^{2}\right)$, with a middle estimate of 0.048 . A correlation plot of the data in Figure 19 is shown in Figure 28, with a linear 
regression yielding a measured slope $C_{V} / N_{V}$ of $0.024 \mu \mathrm{mol} /$ vehicle $\cdot \mathrm{m}^{2}$. As with sensible heat flux, this is well below the low estimate from the inventory, accounting for only $50 \%$ of the middle value. This indicates that fluxes from vehicular emissions are in fact underestimated by the eddy flux measurements.

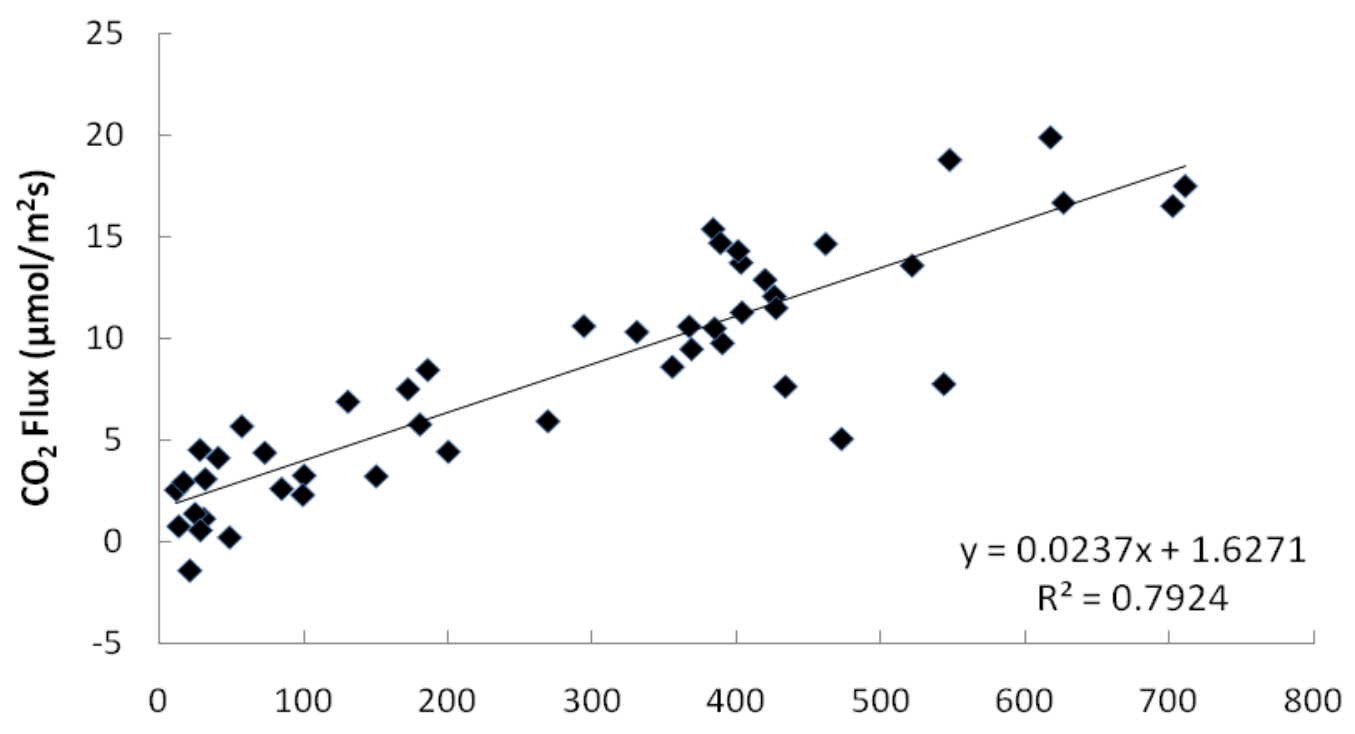

Figure 28: Weekday traffic count versus $\mathrm{CO}_{2}$ Flux. 


\section{Conclusions}

Carbon dioxide concentrations and fluxes exhibited diurnal profiles that are consistent with other urban studies. Average $\mathrm{CO}_{2}$ concentrations were somewhat lower than expected for an urban area, matching the 2009 Mauna Loa background value of $388 \mathrm{ppm}$. The half-hourly $\mathrm{CO}_{2}$ flux was nearly always positive and was strongly correlated to weekday traffic patterns. The average magnitude of $\mathrm{CO}_{2}$ flux $(6.6$ $\left.\mu \mathrm{mol} / \mathrm{m}^{2} \mathrm{~s}\right)$ was slightly lower than urban measurements taken in other cities $(9.3-22$ $\mu \mathrm{mol} / \mathrm{m}^{2} \mathrm{~s}$ ). Filtering for stationary cases increased the average flux to $8.1 \mu \mathrm{mol} / \mathrm{m}^{2} \mathrm{~s}$. Diurnal sensible and latent heat flux profiles showed the expected relationship with the solar cycle. To the extent that results from different cities can be compared, the diurnal cycles and magnitudes of the heat fluxes were consistent with other studies.

Inventory estimates of sensible heat and $\mathrm{CO}_{2}$ fluxes from vehicle emissions both indicated that the flux tower measurements are underestimating both fluxes by over $50 \%$. The data set used for these comparisons was sparse, and as a result averaged weekday traffic profiles and $\mathrm{CO}_{2}$ fluxes were used in place of block-by-block comparisons. These results are intended to be preliminary, not definitive, and a larger data set inclusive of more traffic data will help to confirm or refute this result.

A number of error sources may contribute to the apparent underestimation of fluxes. Neglecting frequency response corrections in postprocessing was estimated to reduce flux by $3-5 \%$ based on correction factors from Aubinet, et al. (2000). The planar fit method for coordinate rotation is thought to be more accurate than the double 
rotation method (Lee et al., 2004). While the effects of different coordinate rotation techniques will not be the same for all situations, Lee et al. (2004) compared the two methods on a sample data set and found that the planar fit method increased fluxes by 4\%. Comparing the measured fluxes with inventory estimates assumes that $\Delta Q_{A}=0$. In the heterogeneous terrain of an urban center this assumption is probably not valid, and may neglect a significant transport mechanism (Paw $U$ et al., 2000). For $\mathrm{CO}_{2}$ flux an additional consideration is that the measurements were taken below the level of most building emissions, a major $\mathrm{CO}_{2}$ source (Pataki et al., 2003). It should also be noted that difficulties with closing the surface energy balance using eddy covariance in general are well documented, even for ideal locations. Even rigorous studies typically fail to close the energy balance by $10-30 \%$ (Foken, 2008b).

More data is needed to verify the measured magnitudes of anthropogenic fluxes from vehicle emissions. As of this writing, eddy flux, solar radiation, and traffic instruments are set up to collect data through the summer of 2010. This study would also benefit from additional analysis of turbulence statistics. Comparisons of the cospectra with established measurements and models would help to identify flow characteristics in the RSL, and should also reveal frequency response errors. Cospectral analysis may also be independently useful to the urban climate community due to the unusual sensor location within the RSL. Coordinate rotation Questions about $\Delta Q_{A}$ could be addressed at least partly by measuring vertical wind, temperature, and gas 
concentration profiles upwind of the current tower as well as at the current tower location. There are currently no plans to take these measurements.

These initial results provide a new sample of wind flow and energy flux characteristics in an urban environment, to be added to a small but growing list of urban flux studies. Though preliminary results indicate that fluxes are underestimated, the measurements are within a factor of two of expected values. Improvements in the processing and analysis are necessary, but the results indicate that meaningful measurements can be obtained within the roughness sublayer. 


\section{References}

Aubinet, M. et al., 2000. Estimates of the Annual Net Carbon and Water Exchange of Forests: The EUROFLUX Methodology. Advances in Ecological Research, 30, pp.11375.

Baldocchi, D., 2008. Lecture 3 Notes: Micrometeorology Flux Measurements, Eddy Covariance Part 1. [Online] Available at: http://nature.berkeley.edu/biometlab/espm228/ [Accessed 5 January 2009].

Baldocchi, D.D., Hicks, B.B. \& Meyers, T.P., 1988. Measuring Biosphere-Atmosphere Exchanges of Biologically Related Gases With Micrometeorological Methods. Ecology, 69(5), pp.1331-40.

Berger, B.W. et al., 2001. Long-Term Carbon Dioxide Fluxes from a Very Tall Tower in a Northern Forest: Flux Measurement Methodology. Journal of Atmospheric and Oceanic Technology, 18, pp.529-42.

Burba, G. \& Anderson, D., 2005. Introduction to the Eddy Covariance Method: General Guidelines and Conventional Workflow. Lincoln, NE: LI-COR Biosciences.

Campbell Scientific, Inc., 2007. CSAT3 Three Dimensional Sonic Anemometer. Logan, UT: Campbell Scientific.

Campbell Scientific, 2008. Model HMP45C Temperature and Relative Humidity Probe. Logan, UT: Campbell Scientific.

Campbell Scientific, 2009. CNR1 Net Radiometer. Logan, UT: Campbell Scientific.

Christen, A. \& Vogt, R., 2004. Energy and Radiation Balance of a Central European City. International Journal of Climatology, 24, pp.1395-421.

Clement, R., 2001. EdiRe Help File. [Online] Edinburgh, U.K.

EIA, 2008a. Motor Gasoline Consumption, Price, and Expenditure Estimates by Sector, 2008. [Online] Available at: http://www.eia.doe.gov/emeu/states/hf.jsp?incfile=sep fuel/html/fuel mg.html [Accessed 8 June 2010].

EIA, 2008b. Oregon Monthly Natural Gas Delivery. [Online] Available at: http://www.eia.doe.gov/dnav/ng/hist/n3045or2m.htm [Accessed 8 June 2010].

EPA, 2009. Light-Duty Automotive Technology, Carbon Dioxide Emissions, and Fuel Economy Trends: 1975 Through 2009. U.S. Environmental Protection Agency.

Finnigan, J.J., 2004. A Re-evaluation of Long-Term Flux Measurement Techniques Part II: Coordinate Systems. Boundary Layer Meteorology, 113, pp.1-41.

Finnigan, J.J. et al., 2003. A Re-Evaluation of Long-Term Flux Measurement Techniques Part I: Averaging and Coordinate Rotation. Boundary-Layer Meteorology, 107, pp.148.

Foken, T., 2008a. Micrometeorology. Berlin: Springer-Verlag.

Foken, T., 2008b. The Energy Balance Closure Problem: An Overview. Ecological Applications, 18(6), pp.1351-67. 
Foken, T. \& Wichura, B., 1996. Tools for Quality Assessment of Surface-Based Flux Measurements. Agricultural and Forest Meteorology, 78, pp.83-105.

Gash, J.H.C., 1986. A Note on Estimating the Effect of a Limited Fetch on Micrometeorological Evaporation Measurements. Boundary-Layer Meteorology, 35, pp.409-13.

George, W.K., 2002. Lectures in Turbulence for the 21st Century. Gothenburg, Sweden: Chalmers University of Technology.

Grimmond, C.S.B., 1992. The Suburban Energy Balance: Methodological Consideration and Results for a Mid-Latitude West Coast City Under Winter and Spring Conditions. International Journal of Climatology, 12(5), pp.481-97.

Grimmond, C.S.B. et al., 2002. Local-Scale Fluxes of Carbon Dioxide in Urban Environments: Methodological Challenges and Results from Chicago. Environmental Pollution, 116, pp.S243-54.

Grimmond, C.S.B., Offerle, B.D., Hom, J. \& Golub, D., 2002. Observations of Local-Scale Heat, Water, Momentum and $\mathrm{CO} 2$ Fluxes at Cub Hill, Baltimore. In Fourth Symposium on the Urban Environment. Norfolk, VA, 2002.

Grimmond, C.S.B. \& Oke, T.R., 1999. Aerodynamic Properties of Urban Areas Derived from Analysis of Surface Form. Journal of Applied Meteorology, 38, pp.1262-92.

Grimmond, C.S.B. et al., 2004. Flux and Turbulence Measurements at a Densely Built-Up Site in Marseille: Heat, Mass (Water and Carbon Dioxide), and Momentum. Journal of Geophysical Research, 109, pp.1-19.

Højstrup, J., 1993. A Statistical Data Screening Procedure. Meas. Sci. Technol., 4, pp.15357.

Horst, T.W., 1997. A Simple Formula for Attenuation of Eddy Fluxes Measured with FirstOrder-Response Scalar Sensors. Boundary-Layer Meteorology, 82, pp.219-33.

Horst, T.W., 2000. On Frequency Response Corrections for Eddy Covariance Flux Measurements. Boundary-Layer Meteorology, 94, pp.517-20.

Hsieh, C.-I., Katul, G. \& Chi, T.-w., 2000. An Approximate Analytical Model for Footprint Estimation of Scalar Fluxes in Thermally Stratified Atmospheric Flows. Advances in Water Resources, pp.765-72.

Ichinose, T., Shimodozono, K. \& Hanaki, K., 1999. Impact of Anthropogenic Heat on Urban Climate in Tokyo. Atmospheric Environment, pp.3897-909.

Kaimal, J.C. \& Finnigan, J.J., 1994. Atmospheric Boundary Layer Flows: Their Structure and Measurement. New York: Oxford University Press.

Kaimal, J.C., Wyngaard, J.C., Izumi, Y. \& Cote, O.R., 1972. Spectral Characteristics of Surface-Layer Turbulence. Quarterly Journal of the Royal Meteorological Society, 98, pp.563-89.

Lee, X., Massman, W. \& Law, B., eds., 2004. Handbook of Micrometeorology. Dordrecht: Kluwer Academic Publishers.

LI-COR, Inc., 2004. LI-7500 CO2/H2O Analyzer. Lincoln, NE: LI-COR.

Massman, W.J., 2000. A Simple Method for Estimating Frequency Response Corrections for Eddy Covariance Systems. Agricultural and Forest Meteorology, 104, pp.185-98. 
Massman, W.J., 2001. Reply to Comment by Rannik on "A Simple Method for Estimating Frequency Response Corrections for Eddy Covariance Systems". Agricultural and Forest Meteorology, 107, pp.247-51.

Massman, W.J. \& Lee, X., 2002. Eddy Covariance Flux Corrections and Uncertainties in Long-Term Studies of Carbon and Energy Exchanges. Agricultural and Forest Meteorology, 113, pp.121-44.

Masson, V., 2000. A Physically-Based Scheme for the Urban Energy Budget in Atmospheric Models. Boundary Layer Meteorology, 94, pp.357-97.

Mauder, M. \& Foken, T., 2004. Documentation and Instruction Manual of the Eddy Covariance Software Package TK2. Bayreuth: Universitat Bayreuth, Abt. Mikrometeorologie.

Mauder, M. \& Foken, T., 2004. Documentation and Instruction Manual of the Eddy Covariance Software Package TK2. Bayreuth University.

McMillen, R., 1988. An Eddy Correlation Technique with Extended Applicability to NonSimple Terrain. Boundary-Layer Meteorology, 43, pp.231-45.

Moncrieff, J., 2006. EdiRe. [Online] Available at: http://www.geos.ed.ac.uk/abs/research/micromet/EdiRe/ [Accessed 2009].

Moore, C.J., 1986. Frequency Response Corrections for Eddy Covariance Systems. Boundary-Layer Meteorology, 37, pp.17-35.

Nemitz, E. et al., 2002. Micrometeorological Measurements of the Urban Heat Budget and $\mathrm{CO} 2$ Emissions on a City Scale. Environmental Science \& Technology, 36, pp.3139-46.

Offerle, B., Grimmond, C.S.B. \& Fortuniak, K., 2005. Heat Storage and Anthropogenic Heat Flux in Relation to the Energy Balance of a Central European City Center. International Journal of Climatology, 25, pp.1405-19.

Offerle, B. et al., 2006. Temporal Variations in Heat Fluxes Over a Central European City Center. Theoretical Applied Climatology, 84, pp.103-15.

Offerle, B., Grimmond, C.S.B., Fortuniak, K. \& Pawlak, W., 2006. Intraurban Differences of Surface Energy Fluxes in a Central European City. Journal of Applied Meteorology and Climatology, 45, pp.125-36.

Oke, T.R., 1988. The Urban Energy Balance. Progress in Physical Geography, pp.471-508.

Oregon Climate Service, 2009. Oregon Climate Service. [Online] Available at: http://ocs.oregonstate.edu/ [Accessed 15 March 2009].

Pataki, D.E., Bowling, D.R. \& Ehleringer, J.R., 2003. Seasonal Cycle of Carbon Dioxide and its Isotopic Composition in an Urban Atmosphere: Anthropogenic and Biogenic Effects. Journal of Geophysical Research, 108(D23).

Paw U, K.T., Baldocchi, D.D., Meyers, T.P. \& Wilson, K.B., 2000. Correction of EddyCovariance Measurements Incorporating Both Advective Effects and Density Fluxes. Boundary Layer Meteorology, 97, pp.487-511.

Pigeon, G., Legain, D., Durand, P. \& Masson, V., 2007. Anthropogenic Heat Release in an Old European Agglomeration (Toulouse, France). International Journal of Climatology, 27, pp.1969-81. 
Pope, S.B., 2000. Turbulent Flows. Cambridge: Cambridge University Press.

Rannik, U., 2001. A Comment on the Paper by W.J. Massman "A Simple Method for Estimating Frequency Response Corrections for Eddy Covariance Systems". Agricultural and Forest Meteorology, 107, pp.241-45.

Raupach, M.R., 1994. Simplified Expressions for Vegetation Roughness Length and ZeroPlane Displacement as Functions of Canopy Height and Area Index. Boundary-Layer Meteorology, 71, pp.211-16.

Raupach, M.R., Antonia, R.A. \& Rajagopalan, S., 1991. Rough-Wall Turbulent Boundary Layers. Applied Mechanics Reviews, 44(1), pp.1-25.

Reid, K.H. \& Steyn, D.G., 1997. Diurnal Variations of Boundary-Layer Carbon Dioxide in a Coastal City - Observations and Comparison with Model Results. Atmospheric Environment, 31, pp.3101-14.

Rotach, M., 1999. On the Influence of the Urban Roughness Sublayer on Turbulence and Dispersion. Atmospheric Environment, 33, pp.4001-08.

Rotach, M.W. et al., 2005. BUBBLE - An Urban Boundary Layer Meteorology Project. Theoretical Applied Climatology, 81, pp.231-61.

Sailor, D.J., 2010. A Review of Methods for Estimating Anthropogenic Heat and Moisture Emissions in the Urban Environment. International Journal of Climatology. In Press.

Sailor, D.J. \& Lu, L., 2004. A Top-Down Methodology for Developing Diurnal and Seasonal Anthropogenic Heating Profiles for Urban Areas. Atmospheric Environment, 38, pp.2737-48.

Sakai, R.K., Fitzjarrald, D.R. \& Moore, K.E., 2001. Importance of Low-Frequency Contributions to Eddy Fluxes Observed over Rough Surfaces. Journal of Applied Meteorology, 40, pp.2178-92.

Schotanus, P., Nieuwstadt, F.T.M. \& De Bruin, H.A.R., 1983. Temperature Measurement With a Sonic Anemometer and its Application to Heat and Moisture Fluxes. Boundary-Layer Meteorology, 26, pp.81-93.

Tanner, C.B. \& Thurtell, G.W., 1969. ECOM 66-G22-F Anemoclinometer Measurements of Reynolds Stress and Heat Transport in the Atmospheric Surface Layer. Research and Development Technical Report. Madison, WI: US Army Electronics Command University of Wisconsin, Madison.

Tans, P., 2009. Trends in Carbon Dioxide. [Online] Available at: http://www.esrl.noaa.gov/gmd/ccgg/trends/ [Accessed 10 June 2010].

Tennekes, H. \& Lumley, J.L., 1972. A First Course in Turbulence. Cambridge, MA: The MIT Press.

Velasco, E. et al., 2005. Measurements of CO2 Fluxes from the Mexico City Urban Landscape. Atmospheric Environment, 39, pp.7433-46.

Vickers, D. \& Mahrt, L., 1997. Quality Control and Flux Sampling Problems for Tower and Aircraft Data. Journal of Atmospheric and Oceanic Technology, 14, pp.512-26.

Vogt, R. et al., 2006. Temporal Dynamics of CO2 Fluxes and Profiles over a Central European City. Theoretical and Applied Climatology, 84, pp.117-26. 
Walsh, C.J., Oke, T.R., Grimmond, C.S.B. \& Salmond, J.A., 2004. Fluxes of Atmospheric Carbon Dioxide Over a Suburban Area of Vancouver. Vancouver, B.C.: University of British Columbia.

Webb, E.K., Pearman, G.I. \& Leuning, R., 1980. Correction of Flux Measurements for Density Effects Due to Heat and Water Vapour Transfer. Quarterly Journal of the Royal Meteorological Society, 106, pp.85-100.

Wilczak, J.M., Oncley, S.P. \& Stage, S.A., 2001. Sonic Anemometer Tilt Correction Algorithms. Boundary Layer Meteorology, 99, pp.127-50. 


\section{Appendix A: Displacement Height Calculations}

Grimmond \& Oke (1999) recommend the method of Raupach (1994) to estimate displacement height $z_{d}$. This method is designed for random building arrangements, requires only four parameters, and compares well with experimental results (Grimmond \& Oke, 1999). It estimates displacement $z_{d}$ as:

$$
z_{d}=\overline{z_{H}}\left[1+\left(\frac{\exp \left[-\left(c_{d 1} 2 \lambda_{F}\right)^{0.5}\right]-1}{\left(c_{d 1} 2 \lambda_{F}\right)^{0.5}}\right)\right]
$$

where $\overline{Z_{H}}$ is the average height of roughness elements (buildings), $\lambda_{F}$ is the frontal area index and $c_{d 1}$ is a free parameter with a recommended value of 7.5. $\lambda_{F}$ is defined as:

$$
\lambda_{F}=\frac{\overline{L_{y}} \overline{Z_{H}}}{\overline{D_{x}} \overline{D_{y}}}
$$

where $\overline{L_{y}}$ is the mean breadth of the roughness elements perpendicular to the wind direction, $\overline{D_{x}}$ is the average interelement spacing (between element centroids) in the alongwind direction, and $\overline{D_{y}}$ is the average in the crosswind direction.

A $500 \mathrm{~m}$ radius was for each of the zones in Figure 14 was established. The parameters $\overline{z_{H}}, \overline{L_{y}}, \overline{D_{x}}$, and $\overline{D_{y}}$ were estimated using data from Google Earth. Results are listed in the table below:

\begin{tabular}{|c|c|c|c|c|c|}
\hline & $\overline{\boldsymbol{Z}_{\boldsymbol{H}}} \mathbf{( m )}$ & $\overline{\boldsymbol{L}_{\boldsymbol{y}}} \mathbf{( m )}$ & $\overline{\boldsymbol{D}_{\boldsymbol{x}}} \mathbf{( m )}$ & $\overline{\boldsymbol{D}_{\boldsymbol{y}}} \mathbf{( m )}$ & $\boldsymbol{z}_{\boldsymbol{d}}(\mathbf{m})$ \\
\hline Zone 1 & 24 & 60 & 85 & 82 & 12.7 \\
\hline Zone 2 & 22 & 60 & 85 & 85 & 11.2 \\
\hline Zone 3 & 11 & 80 & 150 & 100 & 3.9 \\
\hline
\end{tabular}

